\title{
Flora de interesse meliponícola em um fragmento de Mata Atlântica no litoral norte da Bahia, Brasil
}

\author{
Flora of meliponicultural interest in a fragment of Atlantic Forest on the north coast of Bahia, Brazil
}

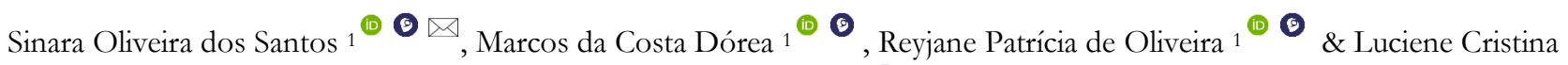
Lima e Lima 2 (1)

1. Universidade Estadual de Feira de Santana, Departamento de Ciências Biológicas, Programa de Pós-Graduação em Botânica, Feira de Santana, Bahia, Brasil

2. Universidade do Estado da Bahia, Departamento de Ciências Exatas e da Terra, Alagoinhas, Bahia, Brasil

Palavras-chave:

Angiospermas. Checklist. Flora melitófila. Meliponíneo. Recurso floral.

\section{Keywords:}

Angiosperms. Checklist. Melitophilous flora. Meliponinae. Floral resource.

Recebido em: 05/07/2021

Aceito em: 19/10/2021

Editora responsável: Cristiana B. N. Costa (UFSB)

eISSN: 2595-6752

\section{(c) (i)}

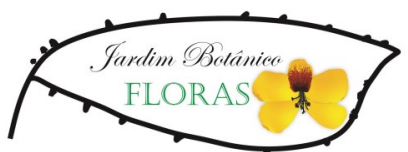

\begin{abstract}
Resumo
O presente estudo teve como objetivo principal conhecer os recursos tróficos, o florescimento e os visitantes florais no entorno de um meliponário situado em um fragmento de Mata Atlântica no litoral norte da Bahia, Brasil. As Angiospermas ocorrentes na área foram marcadas, fotografadas, coletadas, herborizadas, identificadas e depositadas no herbário HUNEB. Foram identificadas 80 espécies, pertencentes a 69 gêneros e 31 famílias, sendo Asteraceae (11), Fabaceae (11) e Rubiaceae (8) as mais representativas em número de espécies. Dentre elas, 30 (37,5\%) tiveram suas flores visitadas por meliponíneos e apresentaram flores durante todo o período estudado: Borreria verticillata (L.) G.Mey., Conocliniopsis prasiifolia (DC.) R.M.King \& H.Rob., Commelina erecta L., Mimosa pudica L., Richardia grandiflora (Cham. \& Schltdl.) Steud. e Turnera subulata Sm. A vegetação herbácea foi a mais representativa $(53,33 \%$ ) e o néctar representou 56,67\% do recurso trófico disponível para essas abelhas, contribuindo para o conhecimento do pasto apícola para a guilda de abelhas na área de estudo.
\end{abstract}

\begin{abstract}
The present study had as main objective to know the trophic resources, flowering and floral visitors around a meliponary, located in an Atlantic Forest fragment on the north coast of Babia, Brazil. Angiosperms occurring in the area were marked, photographed, collected, herborized, identified and deposited in the HUNEB herbarium. Eighty species were identified, belonging to 69 genera and 31 families, with Asteraceae / Fabaceae (11) and Rubiaceae (8) being the most representative in number of species. Among them, 30 (37.5\%) had their flowers visited by meliponines and presented flowers throughout the study period: Borreria verticillata (L.) G.Mey., Conocliniopsis prasiifolia (DC.) R.M.King \& H.Rob., Commelina erecta L., Mimosa pudica L., Richardia grandiflora (Cham. \& Schltdl.) Steud. and Turnera subulata Sm. Herbaceous vegetation was the most representative $(53.33 \%)$, and nectar represented $56.67 \%$ of the trophic resource available to these bees, contributing to the knowledge of bee pasture for the bee guild in the study area.
\end{abstract}




\section{Introdução}

Floras melitófilas consideradas apícolas ou meliponícolas são compostas por espécies vegetais que atraem as abelhas para a coleta de recursos florais como pólen e néctar, sendo estes a base da nutrição desses insetos em todas as suas fases de desenvolvimento (Almeida et al., 2003). O pólen corresponde a uma fonte concentrada de proteínas e o néctar é importante fornecedor de energia (Wiese, 1985; Nogueira-Neto, 1997; Wiese, 2005; Viana et al., 2006). Existem ainda outros recursos florais explorados pelas abelhas, como resinas, óleos e até mesmo essências (Roubik, 1992), sendo as resinas e ceras utilizadas por algumas espécies para construção dos ninhos; lipídios florais são usados como alimento e construção do ninho; e fragrâncias são atrativos para a cópula e marcação de território (Roubik, 1991; Silva et al., 2014).

A identificação das plantas apícolas e/ou meliponícolas de uma dada região tem grande importância na determinação do potencial para a atividade comercial de criação de abelhas, sendo que a mera ocorrência de floresta ou de uma vegetação conservada não assegura àquela área um bom potencial para o desenvolvimento da apicultura ou meliponicultura (Freitas; Silva, 2006). Métodos indiretos são amplamente usados para a identificação da flora apícola/meliponícola e são fundamentados em observações sobre períodos e padrões de florescimento das plantas, morfologia floral, visitação de abelhas às flores e comportamento de forrageio (Freitas; Silva, 2006).

O conhecimento sobre as plantas fornecedoras de recursos florais para a manutenção de comunidades de abelhas em habitats naturais no Brasil ainda é escasso e muitas investigações têm sido conduzidas apenas através de observações dos indivíduos nas flores ou por análises do pólen coletado por esses insetos (Aguiar, 2003). Além do conhecimento das plantas que fornecem recursos tróficos às abelhas, é importante a geração de dados acerca da floração das espécies que compõem o pasto apícola/meliponícola, ou seja, as plantas de interesse às abelhas eussociais, para que seja entendido, por exemplo, o fluxo de pólen e néctar disponível ao longo do ano (Almeida et al., 2003).

A grande diversidade da flora do Brasil e em especial do estado da Bahia, impõe um grande esforço de investigação para suprir as várias lacunas existentes sobre floras locais, regionais e sobre as relações entre plantas e seus polinizadores. A Bahia é um estado com ampla extensão territorial e grande diversidade climática, topográfica e com formações vegetacionais relacionadas a pelo menos três dos grandes biomas brasileiros: Cerrado, Caatinga e Mata Atlântica (Giulietti et al., 2006). A Mata Atlântica é bastante heterogênea, incluindo fitofisionomias de floresta ombrófila, floresta estacional semidecidual e decidual, ocupando atualmente cerca $28 \%$ de seu território original (Rezende et al., 2018). É evidente a ampliação do conhecimento acerca da flora desse bioma nos últimos anos, contudo, para um ambiente com uma riqueza de espécies e endemismos tão alta, ainda pode ser considerado insuficientemente conhecido (Stehmann et al., 2009).

Estudos revelam que a Mata Atlântica ocupava ca. 32\% da área do estado Bahia, tendo $1^{\circ}$ lugar no ranking de desmatamento, devido à supressão da vegetação (Fundação SOS Mata Atlântica \& Instituto Nacional de Pesquisas Espaciais, 2018). Levantamentos florísticos envolvendo a flora desse bioma na Bahia são comumente encontrados na sua região sul, que engloba florestas geralmente úmidas (Coelho; Amorim, 2014; Lopes et al., 2015), ao contrário da região do litoral norte e agreste do estado, cujo número de estudos é substancialmente menor (Alves et al., 2015; Matos et al., 2017), embora a biodiversidade regional seja considerada potencialmente grande (Gomes; Guedes, 2014). Isso coincide com os dados dos levantamentos florísticos e coleções cientificas disponíveis, que não indicam o uso conhecido das espécies, resultando em áreas inteiras ou ecossistemas mal representados em coleções e bancos de dados de biodiversidade (Santos et al., 2011; Oliveira et al., 2016), inclusive sobre as espécies de interesse às abelhas eussociais.

Do mesmo modo, listagens florísticas acompanhadas de registros dos períodos de floração são escassas no Brasil, o que permite por exemplo, que criadores de abelhas possam fazer melhorias em suas atividades, promovendo a alta da produtividade e agregando maiores valores aos produtos (Almeida et al., 2003). Assim, o presente estudo teve por objetivo principal analisar a flora de angiospermas presentes no raio de forrageio de meliponíneos ocorrentes em um fragmento de Mata Atlântica no litoral Norte da Bahia, tendo em vista a ocorrência de um meliponário pré-instalado na área, ampliando assim o conhecimento sobre a composição da flora melitófila local e o período de floração das espécies, correspondente à disponibilidade de recursos florais explorados pelas abelhas nativas.

\section{Material e Métodos}

O estudo foi desenvolvido em um fragmento de Mata Atlântica no município de Alagoinhas, no Território de Identidade Litoral Norte e Agreste Baiano (SEI, 2018). Inclui aproximadamente 50 ha, caracterizado como um complexo vegetacional de domínio da floresta ombrófila densa submontana, com fitofisionomias bem distintas em decorrência da forte influência edafoclimática da área, conforme caracterização de Jesus et al. (2017). Possui um gradiente vegetacional marcado por áreas temporariamente encharcadas com elementos característicos de mata paludosa, vegetação ciliar, brejos e lagoas, e floresta ombrófila densa em estágio médio de regeneração com adensamento de serapilheira e expressivo banco de sementes, localizado no Campus II da Universidade do Estado da Bahia (UNEB) (Figura 1). A região está localizada a uma altitude de $150 \mathrm{~m}$, apresenta os tipos climáticos úmido a subúmido, com um período chuvoso entre março e julho, com totais anuais de chuvas entre $1.234,1 \mathrm{~mm}$ a $1.280 \mathrm{~mm}$ e temperatura média em torno de $24^{\circ} \mathrm{C}$ (SEI, 2018).

$\mathrm{A}$ área de estudo inclui um meliponário previamente instalado (12 10.661 'S $\left.38^{\circ} 24.723^{\prime} \mathrm{W}\right)$ e mantido pela UNEB, o qual inclui colônias de espécies de abelhas nativas devidamente identificadas por especialistas, com espécimes depositados no Laboratório de Estudos Palinológicos (LAEP/Campus II), da Universidade do Estado da Bahia. As seguintes espécies de meliponíneos são mantidas nessas colônias, as quais fornecem suporte para o desenvolvimento de pesquisas envolvendo interações abelha-flor e palinologia aplicada: Frieseomelitta meadewaldoi (Cockerell, 1915), Frieseomelitta doederleini (Friese, 1900), Melipona scutellaris Latreille, 1811, Scaptotrigona xanthotricha Moure, 1950, Tetragonisca angustula (Latreille, 1811), além de Nannotrigona sp. e Plebeia sp.

Devido ao interesse na flora meliponícola, as coletas de plantas envolveram apenas amostras de angiospermas, em um raio de $500 \mathrm{~m}$ no entorno do meliponário local, em trilhas préestabelecidas e de acordo com o raio de forrageio conhecido 


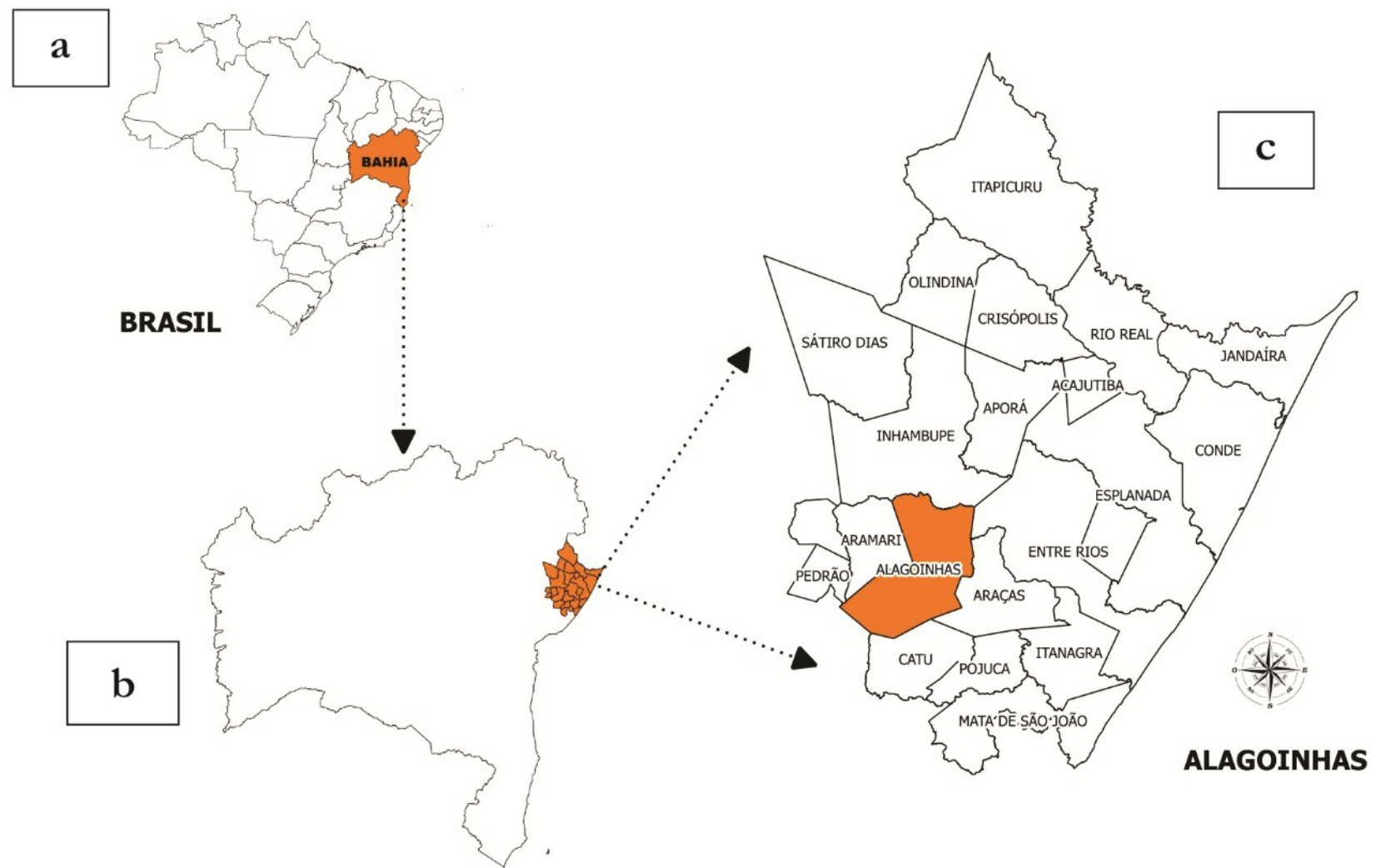

\section{LITORAL NORTE E AGRESTE BAIANO}

Figura 1. Localização da área de estudo: (a) destaque para o estado da Bahia; (b) Território de Identidade Litoral Norte e Agreste Baiano (SEI, 2018); e (c) município de Alagoinhas.

das abelhas presentes no local, segundo Aleixo et al. (2014). As coletas foram realizadas durante 24 meses, em dois períodos distintos, sendo o primeiro de janeiro a dezembro de 2015 , e o segundo de junho de 2017 a maio de 2018. As visitas ao local eram realizadas quinzenalmente, de $06 \mathrm{~h} 00 \mathrm{~min}$ às $10 \mathrm{~h} 00 \mathrm{~min}$, pela manhã, e das $16 \mathrm{~h} 00 \mathrm{~min}$ às $17 \mathrm{~h}: 00 \mathrm{~min}$, no final da tarde, cada amostragem com duração de $5 \mathrm{~h}$, totalizando $120 \mathrm{~h}$ de esforço amostral. Durante as coletas, de cada espécime coletado foram anotadas informações relevantes, como altura, hábito, cor das flores e frutos, data da coleta, dentre outras, conforme as técnicas usuais em botânica (Mori et al., 1989).

A época de florescimento foi observada, sendo as plantas em floração fotografadas, marcadas para acompanhamento da visita de meliponíneos e, em seguida, coletados ramos floríferos para posterior herborização. Todas as amostras de plantas coletadas foram depositadas no Herbário da Universidade do Estado da Bahia, Campus II (HUNEB), e duplicatas enviadas ao Herbário da Universidade Estadual de Feira de Santana (HUEFS) (siglas segundo Thiers, 2021). O material foi identificado com o auxílio de especialistas e a utilização de literatura especializada, além de comparação com os acervos dos herbários citados. Todas as espécies identificadas tiveram os nomes e os respectivos autores conferidos na plataforma da Flora do Brasil 2020 (Flora do Brasil, 2020), onde também foram obtidos os dados sobre distribuição das mesmas.

Os dados relativos aos recursos florais coletados pelas abelhas foram obtidos por meio de observações diretas do comportamento de forrageio desses insetos nas flores. A captura das abelhas durante visita às flores seguiu o método descrito por Sakagami et al. (1967), sendo o tempo de coleta em cada planta entre 5 e $10 \mathrm{~min}$. As abelhas foram enviadas a especialistas para identificação, sendo depositadas na Coleção do Laboratório de Estudos Palinológicos (LAEP), da Universidade do Estado da Bahia (UNEB), Campus II.

Foi realizado o teste de correlação entre as variáveis climáticas (precipitação, umidade e temperatura) do período de estudo com a presença e ausência de flores, calculado através do coeficiente de correlação de Spearman (rs), onde a correlação é considerada significativa se $\mathrm{p}<0,05$. Os valores de $\mathrm{r}$ (coeficiente de correlação), que qualificam as correlações, foram analisados de acordo com Davis (1971): quando $r=0,01$ a 0,09, as correlações são desprezíveis; $r=0,10$ a 0,29 , são fracas; $r=0,30$ a 0,49 , são moderadas; $r=0,50$ a 0,69 , são fortes; $r=0,70$ a 0,99 , são muito fortes; e $r=1,0$ indica correlação perfeita. Para isto, se utilizou o programa PAST (Paleontological Statistics) versão 2.17. Os dados climáticos foram obtidos através do site do Instituto Nacional de Meteorologia (INMET).

\section{Resultados}

A flora de angiospermas no entorno do meliponário analisado é composta por 80 espécies, pertencentes a 69 gêneros e 31 famílias (Tabela 1, Figuras. 2-8). Desse total, 78 espécies foram coletadas no primeiro período de acompanhamento (2015), e 

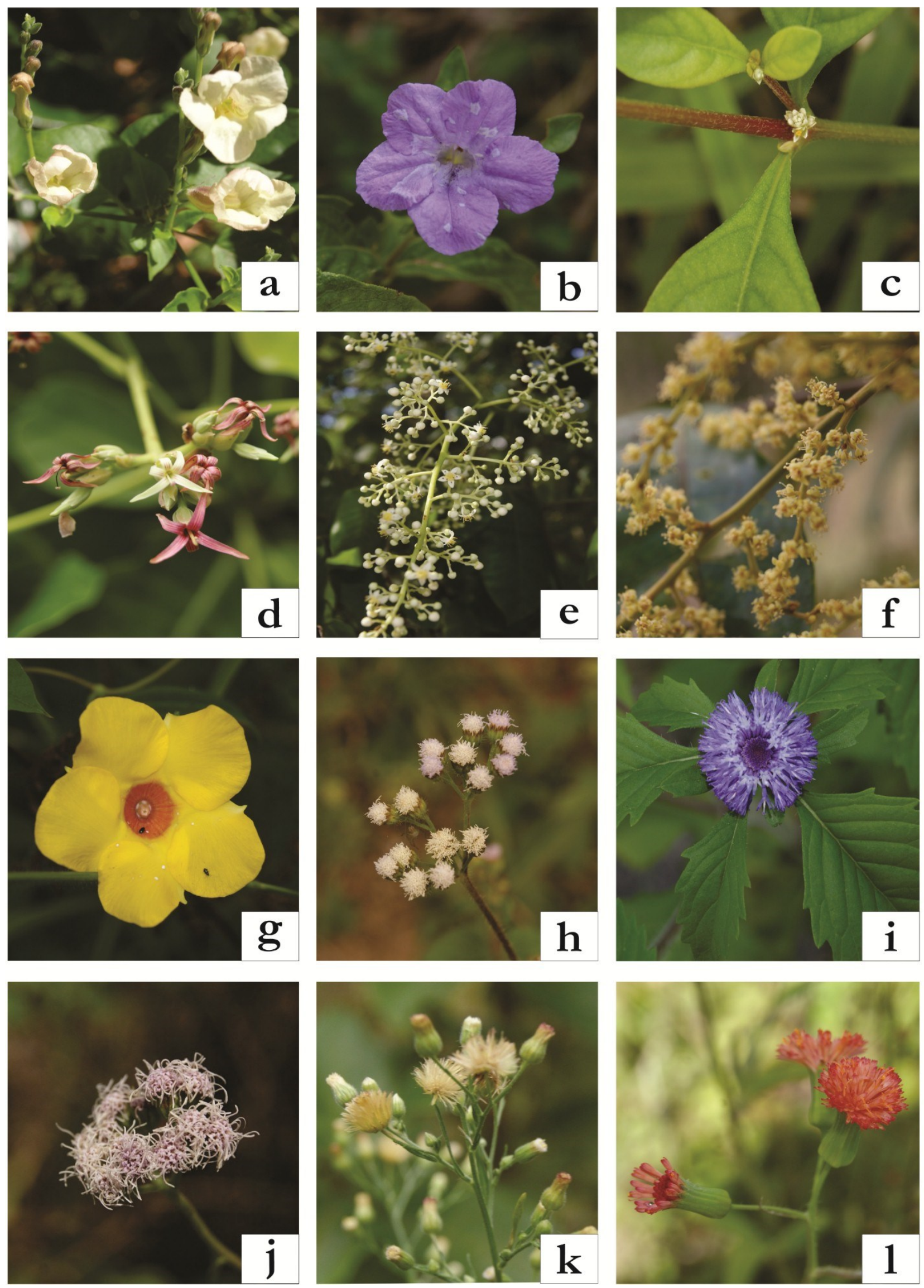

Figura 2. Angiospermas de um fragmento de Mata Atlântica do litoral norte da Bahia, Brasil. Acanthaceae A. Asystasia gangetica (L.) T.Anderson B. Ruellia bahiensis (Nees) Morong Amaranthaceae: C. Alternanthera tenella Colla Anacardiaceae: D. Anacardium occidentale L. E. Spondias tuberosa Arruda F. Tapirira guianensis Aubl. Apocyaceae: G. Mandevilla scabra (Hoffmanns. ex Roem. \& Schult.) K. Schum. Asteraceae: H. Ageratum conyzoides L. I. Centratherum punctatum Cass. J. Conocliniopsis prasiifolia (DC.) R.M.King \& H.Rob. K. Conyza bonariensis (L.) Cronquist; L. Emilia fosbergii Nicolson 

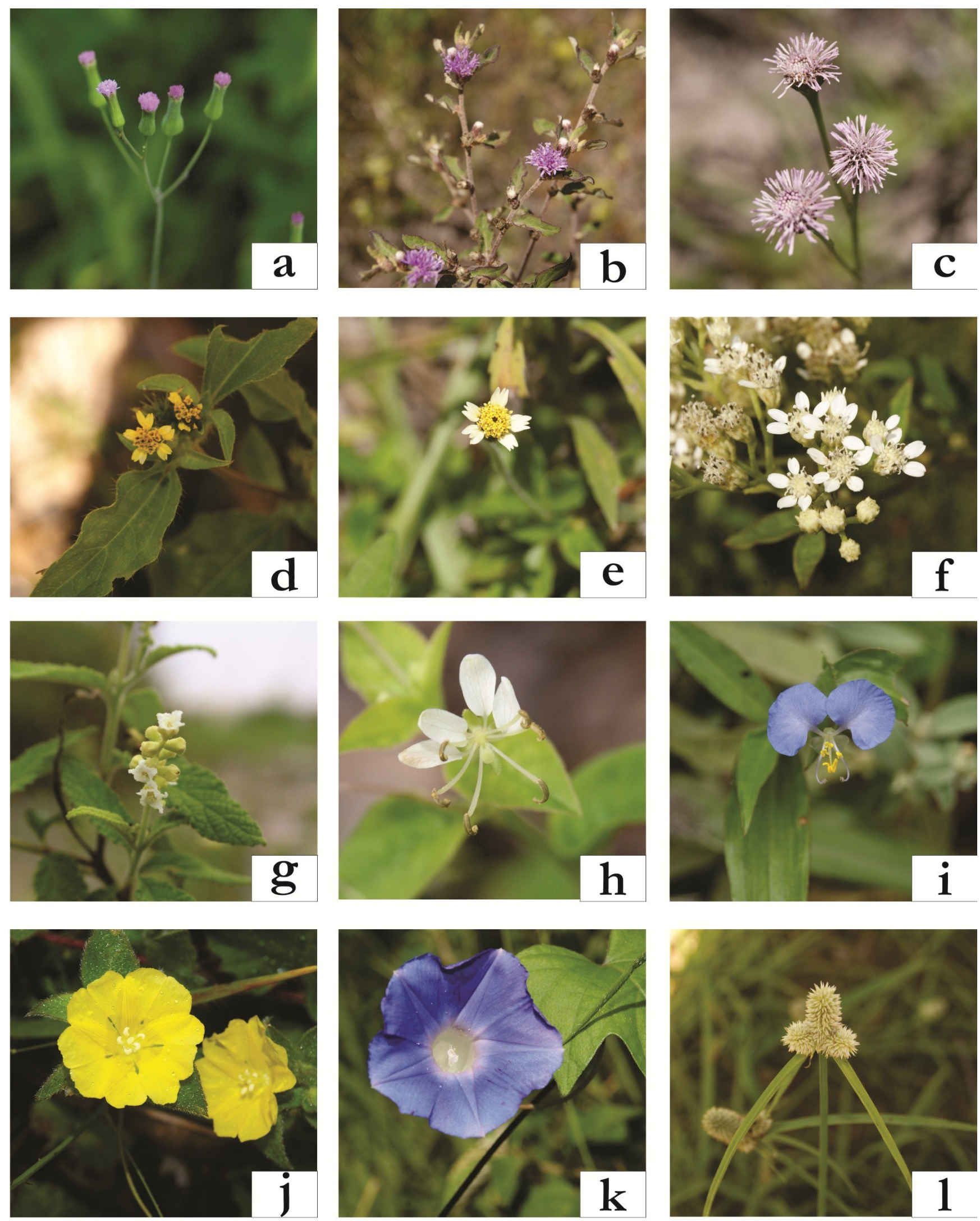

Figura 3. Angiospermas de um fragmento de Mata Atlântica do litoral norte da Bahia, Brasil. Asteraceae: A. Emilia sonchifolia (L.) DC. B. Lepidaploa cotoneaster (Willd. ex Spreng.) H.Rob. C. Platypodanthera melissifolia (DC.) R.M.King \& H.Rob. D. Synedrella nodiflora (L.) Gaertn. E. Tridax procumbens L. F. Verbesina macrophylla (Cass.) S.F.Blake Boraginaceae: G. Varronia curassavica Jacq. Cleomaceae: H. Tarenaya aculeata (L.) Soares Neto \& Roalson Commelinaceae: I. Commelina erecta L. Convolvulaceae: J. Daustinia montana (Moric.) Buril \& A.R. Simões K. Ipomoea nil (L.) Roth Cyperaceae: L. Cyperus sesquiflorus (Torr.) Mattf. \& Kuk. 

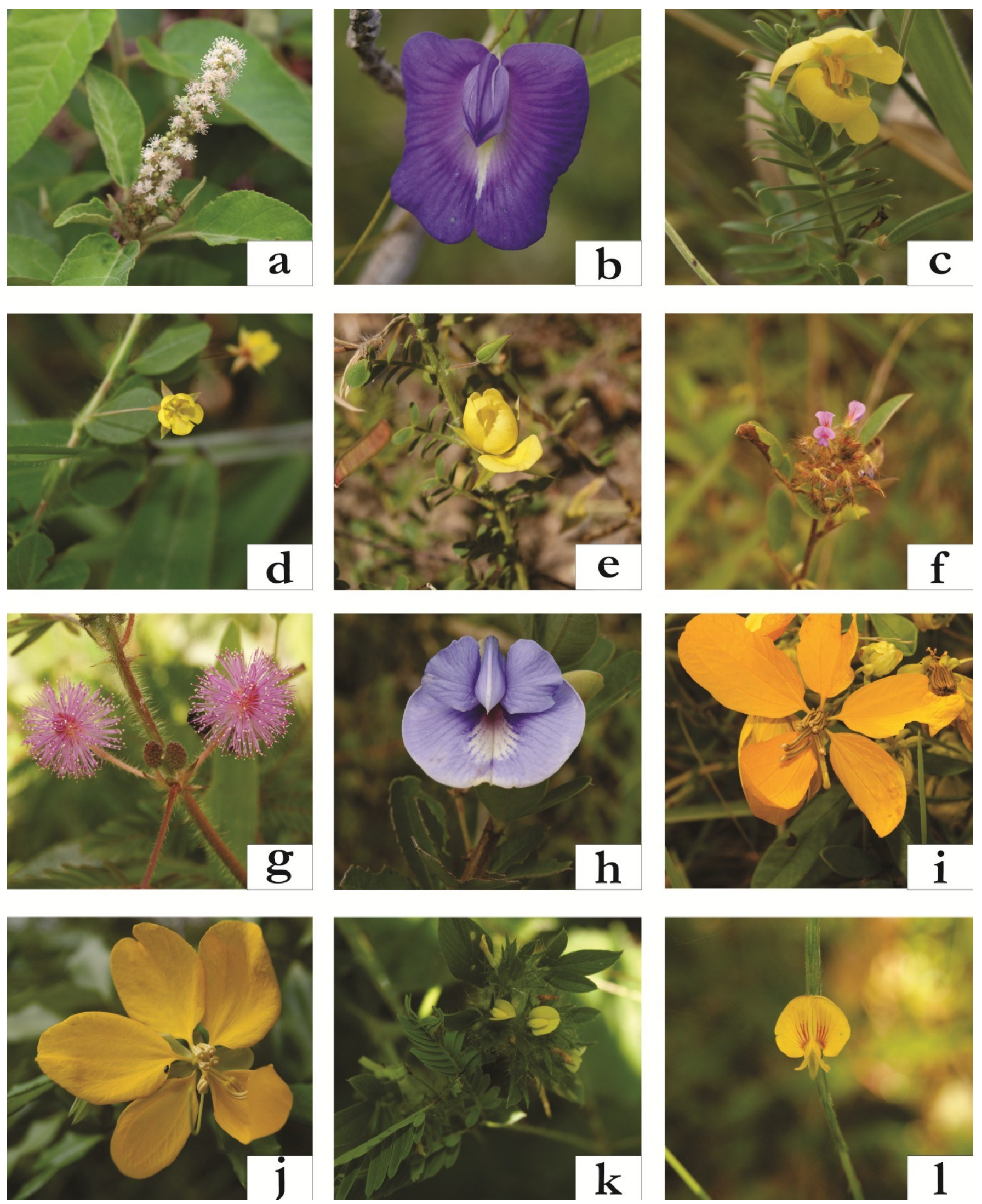

Figura 4. Angiospermas de um fragmento de Mata Atlântica do litoral norte da Bahia, Brasil. Euphorbiaceae: A. Croton heliotropiifolius Kunth Fabaceae: B. Centrosema brasilianum (L.) Benth. C. Chamaecrista flexuosa (L.) Greene D. Chamaecrista rotundifolia (Pers.) Greene E. Chamaecrista swainsonii (Benth.) H.S.Irwin \& Barneby F. Desmodium barbatum (L.) Benth. G. Mimosa pudica L. H. Periandra mediterranea (Vell.) Taub. I. Senna macranthera (DC. ex Collad.) H.S.Irwin \& Barneby J. Senna splendida (Vogel) H.S.Irwin \& Barneby; K. Stylosanthes viscosa (L.) Sw. L. Zornia latifolia Sm. 

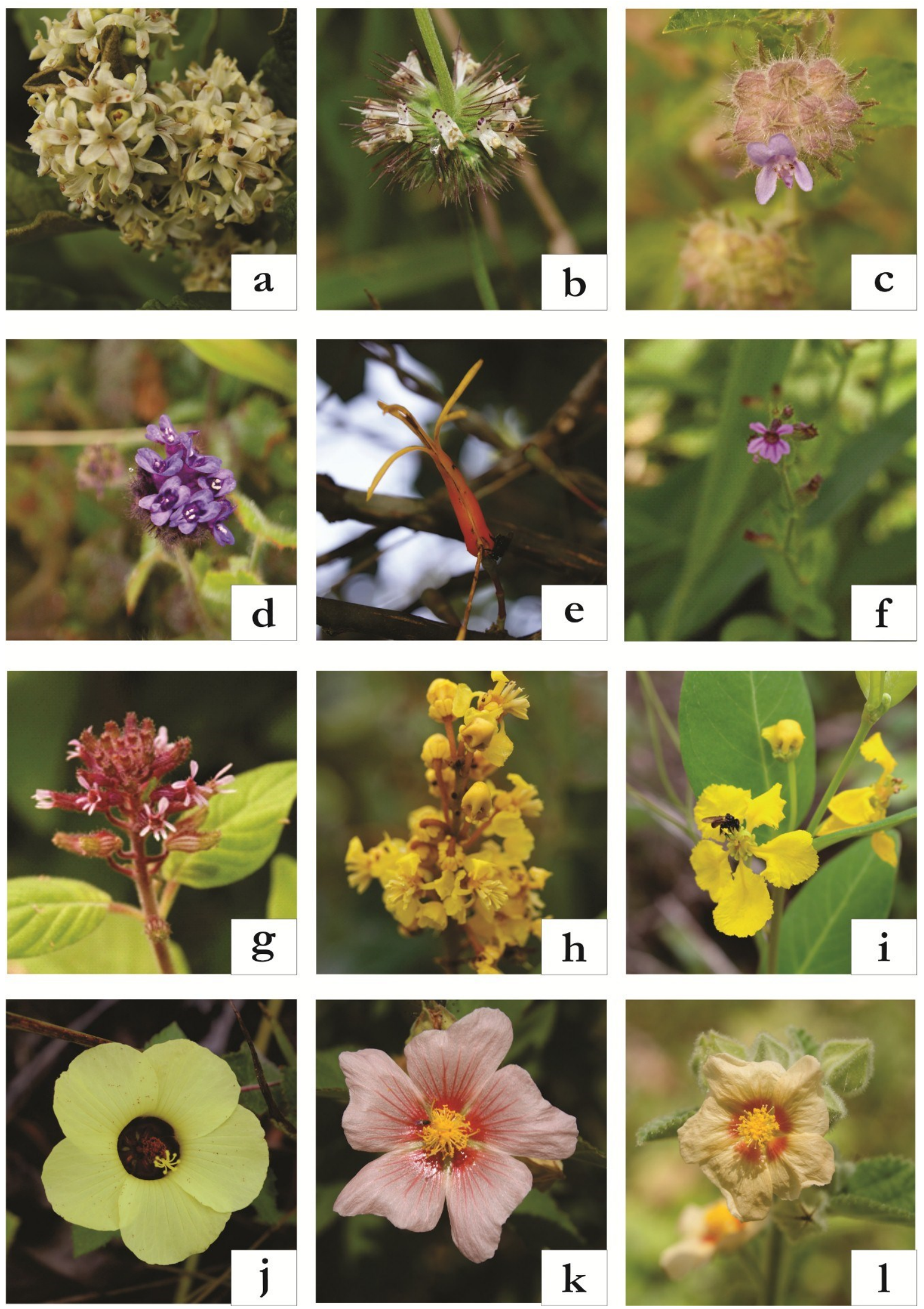

Figura 5. Angiospermas de um fragmento de Mata Atlântica do litoral norte da Bahia, Brasil. Lamiaceae: A. Aegiphila verticillata Vell. B. Gymneia platanifolia (Mart. ex Benth.) Harley \& J.F.B.Pastore C. Marsypianthes chamaedrys (Vahl) Kuntze D. Rhaphiodon Schauer; Loranthaceae: E. Psittacanthus sp Lythraceae: F. Cuphea micrantha Kunth G. Cuphea racemosa (L.f.) Spreng. Malpighiaceae: H. Byrsonima sericea DC. I. Stigmaphyllon paralias A.Juss. Malvaceae: J. Pavonia cancellata (L.) Cav. K. Sida sp. L. Sida cordifolia L. 

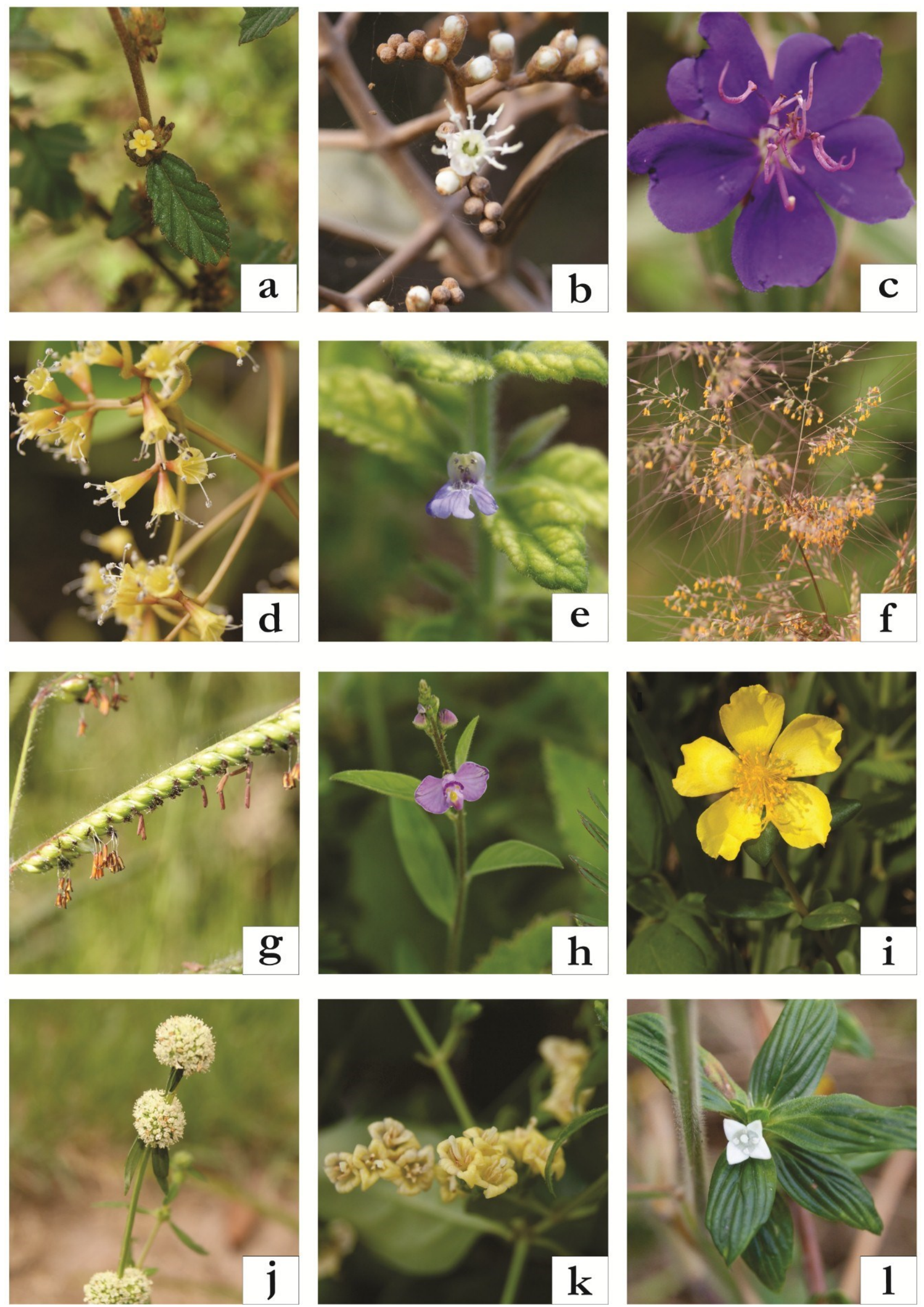

Figura 6. Angiospermas de um fragmento de Mata Atlântica do litoral norte da Bahia, Brasil. Malvaceae: A. Waltheria indica L. Melastomataceae: B. Miconia albicans (Sw.) Triana C. Pleroma lhotzkyanum (C. Presl.) Triana Nyctaginaceae: D. Guapira pernambucensis (Casar.) Lundell Plantaginaceae: E. Stemodia foliosa Benth. Poaceae: F. Melinis minutiflora P. Beauv. G. Urocbloa brizantha (Hochst. ex A. Rich.) R.D.Webster Polygalaceae: H. Polygala sp. Portulacaceae: I. Portulaca umbraticola Kunth Rubiaceae: J. Borreria verticillata (L.) G.Mey. K. Cbiococca alba (L.) Hitchc. L. Hexasepalum radula (Willd.) Delprete \& J.H. Kirkbr. 

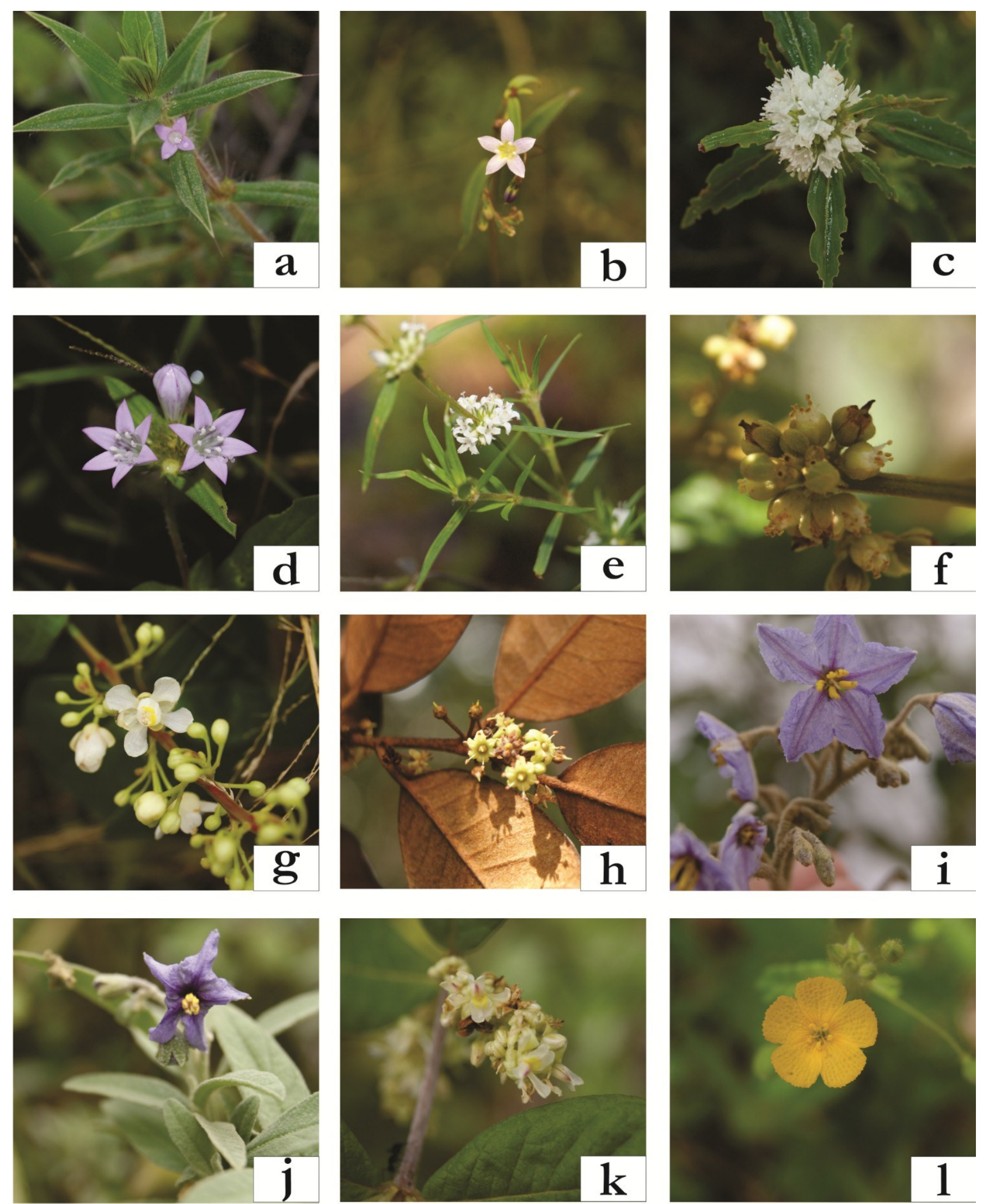

Figura 7. Angiospermas de um fragmento de Mata Atlântica do litoral norte da Bahia, Brasil. Rubiaceae: A. Hexasepalum teres (Walter) J.H. Kirkbr. B. Leptoscela ruellioides Hook.f. C. Mitracarpus strigosus (Thunb.) P.L.R. Moraes, De Smedt \& Hjertson D. Richardia grandiflora (Cham. \& Schltdl.) Steud. E. Staelia virgata (Link ex Roem. \& Schult.) K.Schum. Sapindaceae: F. Cupania racemosa (Vell.) Radlk. G. Serjania salzmanniana Schltdl. Sapotaceae: H. Chrysophyllum rufum Mart. Solanaceae: I. Solanum paniculatum L. J. Solanum stipulaceum Willd. ex Roem. \& Schult. Trigoniaceae: K. Trigonia nivea Cambess. Turneraceae: L. Piriqueta racemosa (Jacq.) Sweet. 

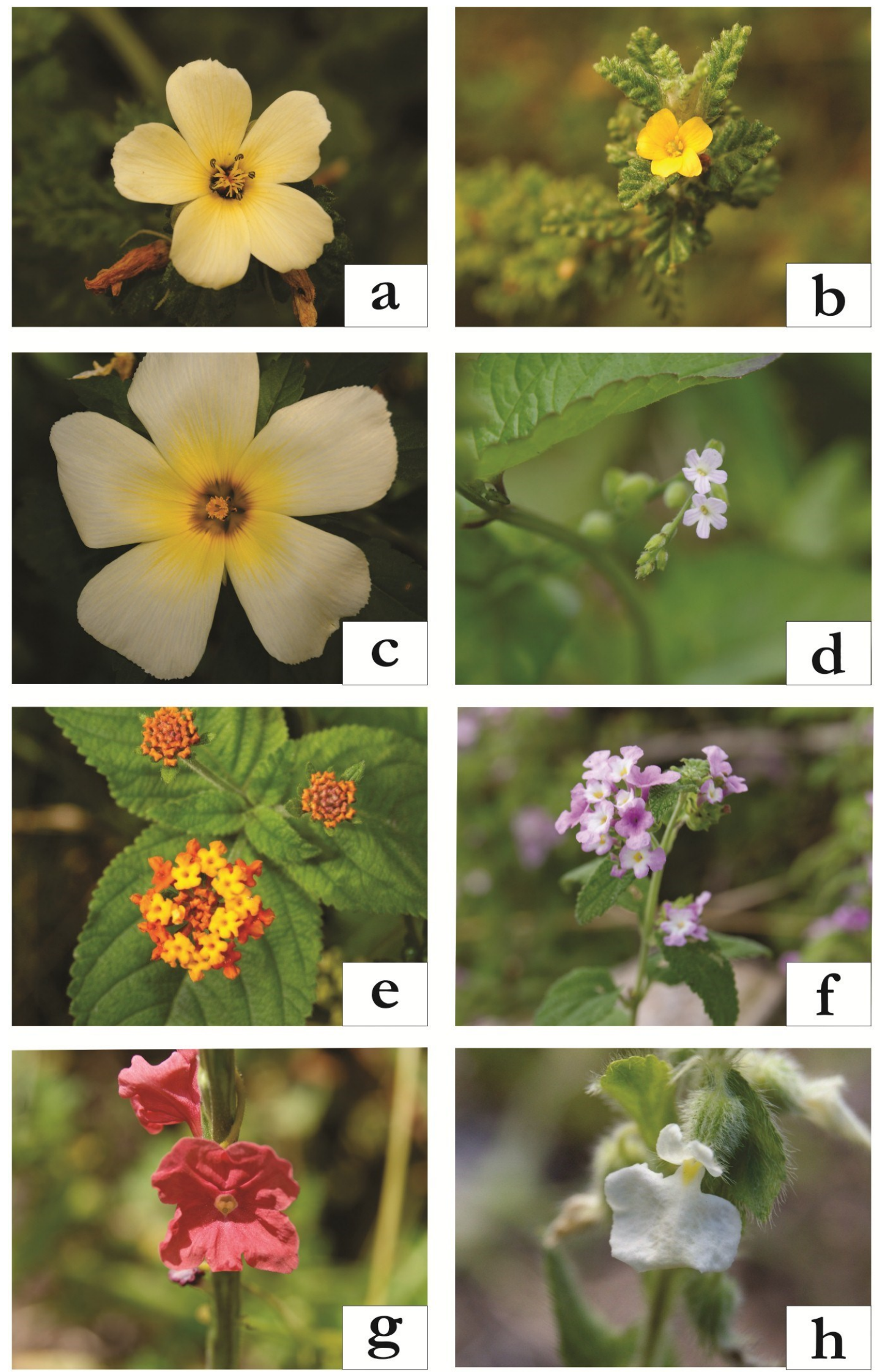

Figura 8. Angiospermas de um fragmento de Mata Atlântica do litoral norte da Bahia, Brasil. Turneraceae: A. Turnera chamaedrifolia Cambess B. Turnera diffusa Willd. ex. Schult C. Turnera subulata Sm. Verbenacae: D. Lantana camara L. E. Lantana fucata Lindl. F. Priva lappulacea (L.) Pers. G. Stachytarpheta microphylla Walp. Violaceae: H. Pombalia calceolaria (L.) Paula-Souza 
Tabela 1. Lista das espécies coletadas em um fragmento de Mata Atlântica do Território Litoral Norte e Agreste Baiano, município de Alagoinhas. Legenda: dados de hábito (arb - arbustivo; subarb - subarbustivo, arv - arbóreo; herb - herbáceo; trep - trepadeira); Recursos florais ofertados (P - pólen; $\mathrm{N}$ - néctar, $\mathrm{P} /$ $\mathrm{N}$ - pólen/néctar; $\mathrm{O}$ - óleo); visitantes florais (Fm - Frieseomelitta meadewaldo; $\mathrm{Ta}$ - Tetragonisca angustula; $\mathrm{Sx}$ - Scaptotrigona xanthotricha; Fd - Frieseomelitta doederleini). * endêmica; ** naturalizada; as demais são nativas do Brasil.

\begin{tabular}{|c|c|c|c|c|}
\hline Família/Espécie & Nome popular & Hábito & Recurso Floral/Referência & Abelha/Visita \\
\hline \multicolumn{5}{|l|}{ Acanthaceae } \\
\hline Asystasia gangetica (L.) T.Anderson** & \multirow[t]{2}{*}{ Coromandel } & herb & N (Shuel, 1970; Freeman et al., 1991) & \\
\hline Ruellia babiensis (Nees) Morong* & & subarb & N (Trip; Manos, 2008) & \\
\hline \multicolumn{5}{|l|}{ Amaranthaceae } \\
\hline Alternanthera tenella Colla & - & herb & $\begin{array}{l}\text { N (Freitas; Silva, 2006; Santos et al., 2006; Maia-Silva et al., } \\
2012 \text { ) }\end{array}$ & Fm; Ta \\
\hline \multicolumn{5}{|c|}{ 2(012) } \\
\hline Anacardium occidentale $\mathrm{L}$. & \multirow{3}{*}{$\begin{array}{l}\text { Cajueiro/caju } \\
\text { Umbuzeiro/ } \\
\text { umbu } \\
\text { Pau-pombo }\end{array}$} & arv & N (Maia-Silva et al., 2012; Silva et al., 2014) & Fm; Ta \\
\hline Spondias tuberosa Arruda* & & arv & P (Braga, 1960; Lorenzi, 2002) & $\mathrm{Sx} ; \mathrm{Ta}$ \\
\hline Tapirira guianensis Aubl. & & arv & P/N (Fernandes et al., 2012) & Fm;Ta; Fd \\
\hline \multicolumn{5}{|l|}{ Apocynaceae } \\
\hline Mandevilla scabra (Hoffmanns. ex Roem. \& Schult.) K.Schum. & - & trep & N (Endress, 1994) & \\
\hline \multicolumn{5}{|l|}{ Asteraceae } \\
\hline Ageratum conyzoides $\mathrm{L}$. & Mentraste/o & herb & P/N (Varalakshmi; Raju, 2013) & \\
\hline Centratherum punctatum Cass. & Balaio-de-velho & herb & $\mathrm{P} / \mathrm{N}$ (Freitas, 1991) & $\mathrm{Ta}$ \\
\hline Conocliniopsis prasiifolia (DC.) R.M.King \& H.Rob.* & Amburana & herb & N (King; Robinson, 1987) & Fm; Ta \\
\hline Conyza bonariensis (L.) Cronquist & Buva/Enxota & arb & P/N (Meneguzzo, 2013) & Fm; Ta \\
\hline Lepidaploa cotoneaster (Willd. ex Spreng.) H.Rob. & - & arb & P/N (Melo, 2008) & $\mathrm{Sx} ; \mathrm{Ta}$ \\
\hline Platypodanthera melissifolia (DC.) R.M.King \& H.Rob.* & - & herb & & \\
\hline Synedrella nodiflora (L.) Gaertn. & Folha-da-feiticeira & herb & & \\
\hline Tridax procumbens L.** & Erva-de-touro & herb & & \\
\hline Verbesina macrophylla (Cass.) S.F.Blake & - & arb & P (Santana; Almeida, 2016) & Fm;Ta; Sx \\
\hline \multicolumn{5}{|l|}{ Boraginaceae } \\
\hline Varronia curassavica Jacq. & - & subarb & N (Hoeltgebaum et al., 2016) & Sx; Ta \\
\hline \multicolumn{5}{|l|}{ Cleomaceae } \\
\hline Tarenaya aculeata (L.) Soares Neto \& Roalson & $\begin{array}{l}\text { Mussambê/ } \\
\text { Sojinha }\end{array}$ & herb & $\mathrm{P} / \mathrm{N}$ (Cane, 2008) & \\
\hline \multicolumn{5}{|l|}{ Commelinaceae } \\
\hline Commelina erecta $\mathrm{L}$. & Trapoeraba & herb & N (Maia-Silva et al., 2012) & $\mathrm{Sx} ; \mathrm{Ta}$ \\
\hline \multicolumn{5}{|l|}{ Convolvulaceae } \\
\hline Daustinia montana (Moric.) Buril \& A.R. Simões* & & trep & P/N (Silva et al., 2010; Maia-Silva et al., 2012) & \\
\hline Ipomoea nil (L.) Roth & - & trep & P/N (Maia-Silva et al., 2012) & \\
\hline \multicolumn{5}{|l|}{ Cyperaceae } \\
\hline Cyperus sesquiflorus (Torr.) Mattf. \& Kuk. & Capim-cheiroso & herb & & \\
\hline Centrosema brasilianum (L.) Benth. & Jequitirana & trep & N (Maia-Silva et al., 2012) & $\mathrm{Ta}$ \\
\hline Chamaecrista flexuosa (L.) Greene & Peninha & herb & P (Aguiar; Gaglianone, 2003; Aguiar et al., 2003) & $\mathrm{Ta}$ \\
\hline Chamaecrista rotundifolia (Pers.) Greene & Erva-de-coração & herb & P (Aguiar; Gaglianone, 2003; Aguiar et al., 2003) & Fm; Ta; $\mathrm{Sx}$ \\
\hline Chamaecrista swainsonii (Benth.) H.S.Irwin \& Barneby* & - & herb & P (Aguiar; Gaglianone, 2003; Aguiar et al., 2003) & \\
\hline Desmodium barbatum (L.) Benth. & Barbadinho & herb & & \\
\hline Mimosa pudica $\mathrm{L}$. & Dormideira & herb & P/N (Vidal et al., 2008) & \\
\hline Periandra mediterranea (Vell.) Taub. & Alcaçuz & arb & & \\
\hline Senna macranthera (DC. ex Collad.) H.S.Irwin \& Barneby & São-João & arb & P (Maia-Silva et al., 2012) & $\mathrm{Ta}$ \\
\hline Senna splendida (Vogel) H.S.Irwin \& Barneby & Fedegoso-bravo & arv & P (Aguiar et al.; 2003; Machado; Lopes, 2006) & $\mathrm{Ta}$ \\
\hline Stylosanthes viscosa (L.) Sw. & Melosa & herb & N (Maia-Silva et al., 2012) & \\
\hline Zornia latifolia Sm. & Arroz-do-campo & herb & N (Aguiar et al.; 2003; Machado; Lopes, 2006) & \\
\hline Lamiaceae & & & & \\
\hline Aegiphila verticillata Vell. & Milho-de-grilo & arb & & \\
\hline Gymneia platanifolia (Mart. ex Benth.) Harley \& J.F.B.Pastore & - & herb & & \\
\hline Marsypianthes chamaedrys (Vahl) Kuntze & Amargosa & herb & N (Freitas 1991; Maia-Silva et al., 2012) & $\mathrm{Ta}$ \\
\hline Rhaphiodon echinus (Nees \& Mart.) Shauer & Falsa menta & herb & N (King; Robinson, 1987; Santos et al., 2006) & Sx; Ta \\
\hline Loranthaceae & & & & \\
\hline Psittacanthus sp. & $\begin{array}{l}\text { Erva-de- } \\
\text { passarinho }\end{array}$ & trep & N (Azpeitia; Lara, 2006) & Sx \\
\hline Lythraceae & & & & \\
\hline Cuphea micrantha Kunth & - & herb & P/N (Almeida; Machado, 2005) & \\
\hline Cuphea racemosa (L.f.) Spreng. & Sete-sangrias & herb & & \\
\hline Malpighiaceae & & & & \\
\hline Byrsonima sericea DC. & Murici & arb & P/O (Costa et al., 2006; Machado; Lopes, 2006) & \\
\hline Stigmaphyllon paralias A.Juss.* & - & herb & O (Costa et al., 2006) & \\
\hline Malvaceae & & & & \\
\hline Pavonia cancellata (L.) Cav. & Corda-de-viola & herb & P/N (Maia-Silva et al., 2012) & \\
\hline Sida sp. & Malva-rosa & arb & & \\
\hline Sida cordifolia $\mathrm{L}$. & - & herb & P/N (Maia-Silva et al., 2012) & \\
\hline Waltheria indica $\mathrm{L}$. & Douradinha & herb & N (Freitas; Silva, 2006; Machado; Lopes, 2006) & $\mathrm{Fm} ; \mathrm{Ta}$ \\
\hline Melastomataceae & & & & \\
\hline Miconia albicans (Sw.) Triana & Canela-de-velho & arb & P (Buchmann, 1983) & \\
\hline Pleroma lhotzkyanum (C. Presl.) Triana* & Quaresmeira & arb & P (Buchmann, 1983) & \\
\hline
\end{tabular}


Tabela 1. Lista das espécies coletadas em um fragmento de Mata Atlântica do Território Litoral Norte e Agreste Baiano, município de Alagoinhas. Legenda: dados de hábito (arb - arbustivo; subarb - subarbustivo, arv - arbóreo; herb - herbáceo; trep - trepadeira); Recursos florais ofertados ( $\mathrm{P}$ - pólen; $\mathrm{N}$ - néctar, P/ $\mathrm{N}$ - pólen/néctar; $\mathrm{O}$ - óleo); visitantes florais (Fm - Frieseomelitta meadewaldoi; $\mathrm{Ta}$ - Tetragonisca angustula, $\mathrm{Sx}$ - Scaptotrigona xanthotricha; $\mathrm{Fd}-$ Frieseomelitta doederleini). * endêmica; ** naturalizada; as demais são nativas do Brasil.

Continuacão

\begin{tabular}{|c|c|c|c|c|}
\hline Família/Espécie & Nome popular & Hábito & Recurso Floral/Referência & Abelha/Visita \\
\hline \multicolumn{5}{|l|}{$\overline{\text { Nyctaginaceae }}$} \\
\hline Guapira pernambucensis (Casar.) Lundell* & - & arb & P/N (Covre; Guerra, 2016) & \\
\hline \multicolumn{5}{|l|}{ Plantaginaceae } \\
\hline Stemodia foliosa Benth. & Meladinha & herb & & \\
\hline \multicolumn{5}{|l|}{ Poaceae } \\
\hline Melinis minutiflora P.Beauv.** & Capim-gordura & herb & P (Bogdan, 1962) & \\
\hline Urocbloa brizantha (Hochst. ex A. Rich.) R.D.Webster** & Alpiste & herb & P (Bogdan, 1962) & $\mathrm{Ta}$ \\
\hline \multicolumn{5}{|l|}{ Polygalaceae } \\
\hline \multicolumn{5}{|l|}{ Portulacaceae } \\
\hline Portulaca umbraticola Kunth & Meio-dia & herb & & \\
\hline \multicolumn{5}{|l|}{ Rubiaceae } \\
\hline Borreria verticillata (L.) G.Mey. & Cabeça de velho & herb & $\begin{array}{l}\text { N (Santos et al., 2006; Maia-Silva et al., 2012; Santos et al., } \\
2018 \text { ) }\end{array}$ & Fm; Ta \\
\hline Chiococca alba (L.) Hitchc. & - & arb & & \\
\hline Hexasepalum radula (Willd.) Delprete \& J.H.Kirkbr. & Erva-de-largato & herb & & $\mathrm{Sx} ; \mathrm{Ta}$ \\
\hline Hexasepalum teres (W alter) J.H.Kirkbr. & Mata-pasto & herb & N (Santos et al., 2006; Maia-Silva et al., 2012) & \\
\hline Leptoscela ruellioides Hook.f.* & - & herb & & \\
\hline Richardia grandiflora (Cham. \& Schltdl.) Steud. & Asa de pato & herb & P/N (Kissmann; Groth, 2000; Lorenzi, 2000) & Fm; Ta; $\mathrm{Sx}$ \\
\hline Staelia virgata (Link ex Roem. \& Schult.) K.Schum. & - & herb & & \\
\hline \multicolumn{5}{|l|}{ Sapindaceae } \\
\hline Cupania racemosa (Vell.) Radlk.* & Caboatã & arb & & \\
\hline Serjania salzmanniana Schltdl.* & $\begin{array}{l}\text { Laranjeira-do- } \\
\text { mato }\end{array}$ & trep & N (Freitas; Silva, 2006) & $\mathrm{Fm} ; \mathrm{Ta}$ \\
\hline \multicolumn{5}{|l|}{ Sapotaceae } \\
\hline Chrysophyllum rufum Mart.* & - & arv & & \\
\hline \multicolumn{5}{|l|}{ Solanaceae } \\
\hline Solanum paniculatum L. & Jurubeba & arb & P (Nunes-Silva et al., 2010) & $\mathrm{Ta}$ \\
\hline Solanum stipulaceum Willd. ex Roem. \& Schult.* & Jurubeba & arb & P (Nunes-Silva et al., 2010) & \\
\hline \multicolumn{5}{|l|}{ Trigoniaceae } \\
\hline Trigonia nivea Cambess. & Cipó-prata & arb & N (Lleras, 1978) & \\
\hline \multicolumn{5}{|l|}{ Turneraceae } \\
\hline Piriqueta racemosa (Jacq.) Sweet & $\begin{array}{l}\text { Erva-de são- } \\
\text { cristovão }\end{array}$ & herb & & \\
\hline Turnera chamaedrifolia Cambess.* & - & herb & & \\
\hline Turnera diffusa Willd. ex. Schult. & Damiana & herb & & \\
\hline Lantana camara L.** & Cambará & subarb & N (Barrows 1976) & $\mathrm{Ta}$ \\
\hline Lantana fucata Lindl. & Cidreira-brava & subarb & & \\
\hline Priva lappulacea (L.) Pers. & Carrapicho & herb & & \\
\hline Stachytarpheta microphylla Walp.* & - & herb & & \\
\hline \multicolumn{5}{|l|}{ Violaceae } \\
\hline Pombalia calceolaria (L.) Paula-Souza & Ipecá-da-praia & herb & & \\
\hline
\end{tabular}

apenas duas (Cupania racemosa (Vell.) Radlk. e Chrysophyllum rufum Mart.), foram adicionadas à lista no segundo período de observação (2017-2018). Dentre as espécies analisadas, 5\% foram subarbustivas, 7,5\% arbóreas, 7,5\% trepadeiras, $20 \%$ arbustivas e $60 \%$ herbáceas (Tabela 1). As famílias mais representativas no entorno do meliponário foram Asteraceae (11 spp.) e Fabaceae (11 spp.), seguidas de Rubiaceae (8 spp.), representando 37,5\% do total de espécies amostradas. Os gêneros Chamaecrista Moench e Turnera L. foram representados por três espécies cada; Emilia (Cass.) Cass., Senna Mill., Cuphea P.Browne, Sida L., Hexasepalum Bartl. ex DC., Solanum L. e Lantana L., por duas espécies cada, enquanto para os demais foi registrada apenas uma espécie (Tabela 1). A maioria das espécies aqui listadas como ocorrentes no entorno do meliponário pertence à flora nativa do Brasil (70 espécies, 87,5\%), sendo 17 delas $(21,25 \%)$ endêmicas do país e apenas duas, Pleroma lhotskyanum (Melastomataceae) e Guapira pernambucensis (Nyctaginaceae), endêmicas da Mata Atlântica. Entre as outras 15 spp. endêmicas do Brasil encontradas na área, oito ocorrem na Mata Atlântica, Caatinga e Cerrado; uma espécie, na Mata Atlântica, Cerrado e Amazônia; cinco, na Caatinga e Cerrado; e uma é endêmica da Caatinga.

Observando o comportamento do florescimento das 80 espécies, no primeiro período de observação (2015), o mês com o maior número de espécies em floração foi dezembro (65 spp.) e o menor, fevereiro (23 spp.). No entanto, para o segundo período de acompanhamento (2017/2018), o mês com maior número de plantas em floração foi setembro de 2017 (63 spp.), e o menor, abril de 2018 (31 spp.) (Figuras 9-10). Dentre essas 80 espécies observadas, apenas seis estiveram em floração durante todo o período de acompanhamento: Borreria verticillata, Commelina erecta, Conocliniopsis prasiifolia, Mimosa pudica, Richardia grandiflora e Turnera subulata. Algumas espécies tiveram um período de floração mais curto, como foi observado para Mandevilla scabra (Apocynaceae), que floresceu nos meses de abril e maio, e Pleroma lhotzkyanum, de setembro a novembro em ambos os períodos estudados, enquanto Trigonia nivea (Trigoniaceae) floresceu apenas de abril a junho de 2015 (Tabela 2). 
Tabela 2. Dados dos registros de florescimento das espécies em um fragmento de Mata Atlântica do litoral norte e agreste da Bahia (* - floração)

\begin{tabular}{|c|c|c|c|c|c|c|c|c|c|c|c|c|c|c|c|c|c|c|c|c|c|c|c|c|}
\hline \multirow{2}{*}{ Espécie/ Período de Observação } & \multicolumn{12}{|c|}{2015} & \multicolumn{12}{|c|}{$2017 / 2018$} \\
\hline & $\mathbf{J}$ & $\mathbf{F}$ & $\mathbf{M}$ & $\mathbf{A}$ & $\mathbf{M}$ & $\mathbf{J}$ & $\mathbf{J}$ & $\mathbf{A}$ & $\mathbf{S}$ & $\mathbf{O}$ & $\mathbf{N}$ & $\mathbf{D}$ & $\mathbf{J}$ & $\mathbf{J}$ & $\mathbf{A}$ & $\mathbf{S}$ & $\mathbf{O}$ & $\mathbf{N}$ & D & $\mathbf{J}$ & $\mathbf{F}$ & $\mathbf{M}$ & $\mathbf{A}$ & $\mathbf{M}$ \\
\hline \multicolumn{25}{|l|}{ Boraginaceae } \\
\hline Varronia curassavica Jacq. & & $*$ & $*$ & $*$ & $*$ & $*$ & $*$ & * & & & & $*$ & $*$ & $*$ & * & $*$ & $*$ & * & * & & $*$ & $*$ & & \\
\hline \multicolumn{25}{|l|}{ Cleomaceae } \\
\hline Tarenaya aculeata (L.) Soares Neto \& Roalson & & & & $*$ & $*$ & $*$ & & & & & & * & & & & $*$ & $*$ & $*$ & & & & & $*$ & $*$ \\
\hline \multicolumn{25}{|l|}{ Commelinaceae } \\
\hline Commelina erecta $\mathrm{L}$. & & $*$ & $*$ & $*$ & $*$ & $*$ & $*$ & $*$ & $*$ & $*$ & $*$ & $*$ & $*$ & $*$ & * & $*$ & $*$ & $*$ & * & $*$ & $*$ & $*$ & $*$ & $*$ \\
\hline \multicolumn{25}{|l|}{ Convolvulaceae } \\
\hline Daustinia montana (Moric.) Buril \& A.R. Simões & & & & & & & & & $*$ & $*$ & * & $*$ & & & & $*$ & & & & & & & & \\
\hline Ipomoea nil (L.) Roth & & & & & & & & * & $*$ & & & $*$ & $*$ & $*$ & $*$ & $*$ & & & & & $*$ & $*$ & & \\
\hline \multicolumn{25}{|l|}{ Cyperaceae } \\
\hline Cyperus sesquiflorus (Torr.) Mattf. \& Kük. & & & & 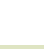 & $*$ & $*$ & $*$ & $*$ & & & & . & $*$ & $*$ & & & & & & & & & & $*$ \\
\hline \multicolumn{25}{|l|}{ Euphorbiaceae } \\
\hline Croton beliotropiifolius Kunth & $*$ & $*$ & $*$ & $*$ & $*$ & $*$ & $*$ & $*$ & $*$ & $*$ & $*$ & $*$ & & $*$ & $*$ & $*$ & $*$ & $*$ & $*$ & & 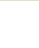 & $*$ & $*$ & $*$ \\
\hline \multicolumn{25}{|l|}{ Fabaceae } \\
\hline Centrosema brasilianum (L.) Benth. & & & $*$ & $*$ & & & & & & $*$ & $*$ & $*$ & . & & & $*$ & & $*$ & & & & $*$ & $*$ & $*$ \\
\hline Chamaecrista flexuosa (L.) Greene & $*$ & & $*$ & $*$ & $*$ & $*$ & $*$ & * & $*$ & $*$ & $*$ & $*$ & & $*$ & $*$ & $*$ & $*$ & $*$ & $*$ & & $*$ & $*$ & $*$ & \\
\hline Chamaecrista rotundifolia (Pers.) Greene & & & & & & & $*$ & $*$ & $*$ & $*$ & $*$ & $*$ & $*$ & $*$ & $*$ & $*$ & $*$ & $*$ & $*$ & $*$ & $*$ & $*$ & & \\
\hline Chamaecrista swainsonii (Benth.) H.S.Irwin \& Barneby & & & & & & & $*$ & * & $*$ & & & 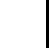 & & & $*$ & $*$ & $*$ & & & & & & & \\
\hline Desmodium barbatum (L.) Benth. & & & & & $*$ & $*$ & $*$ & * & $*$ & $*$ & * & $*$ & 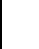 & & & $*$ & $*$ & * & $*$ & $*$ & $*$ & $*$ & & \\
\hline Mimosa pudica L. & $*$ & $*$ & $*$ & $*$ & $*$ & $*$ & $*$ & * & $*$ & $*$ & $*$ & $*$ & $*$ & $*$ & * & $*$ & $*$ & $*$ & * & * & $*$ & $*$ & $*$ & $*$ \\
\hline Periandra mediterranea (Vell.) Taub. & $*$ & & $*$ & & & & & $*$ & $*$ & $*$ & * & $*$ & 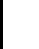 & & $*$ & $*$ & $*$ & $*$ & $*$ & $*$ & $*$ & $*$ & & \\
\hline Senna macranthera (DC. ex Collad.) H.S.Irwin \& Barneby & & & & & & & $*$ & * & & & & $*$ & 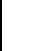 & & $*$ & $*$ & $*$ & & & & & & & \\
\hline Senna splendida (Vogel) H.S.Irwin \& Barneby & & & $*$ & $*$ & $*$ & $*$ & & * & $*$ & $*$ & * & $*$ & 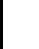 & & & & & & & $*$ & $*$ & & & \\
\hline Stylosanthes viscosa (L.) Sw. & & & & & & & $*$ & * & $*$ & $*$ & * & $*$ & $*$ & $*$ & $*$ & $*$ & $*$ & $*$ & $*$ & $*$ & $*$ & $*$ & & \\
\hline Zornia latifolia Sm. & & & & 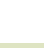 & $*$ & $*$ & $*$ & $*$ & $*$ & $*$ & $*$ & $*$ & & $*$ & $*$ & $*$ & $*$ & $*$ & $*$ & $*$ & $*$ & $*$ & 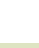 & \\
\hline \multicolumn{25}{|l|}{ Lamiaceae } \\
\hline Aegiphila verticillata Vell. & & & $*$ & $*$ & $*$ & & 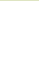 & & & & & & & $*$ & & & & & & & & & & \\
\hline Gymneia platanifolia (Mart. ex Benth.) Harley \& J.F.B.Pastore & & & & & & & & & $*$ & $*$ & & $*$ & & & $*$ & $*$ & $*$ & $*$ & & & $*$ & & & \\
\hline Marsypianthes chamaedrys (Vahl) Kuntze & & & & & & $*$ & $*$ & $*$ & $*$ & $*$ & $*$ & $*$ & & & $*$ & $*$ & $*$ & $*$ & $*$ & $*$ & $*$ & $*$ & $*$ & $*$ \\
\hline Rhaphiodon echinus Schauer & & & & & $*$ & $*$ & $*$ & $*$ & $*$ & $*$ & $*$ & $*$ & & & $*$ & $*$ & $*$ & $*$ & $*$ & $*$ & $*$ & $*$ & $*$ & $*$ \\
\hline Loranthaceae & & & & & & & & & & & & & & & & & & & & & & & & \\
\hline Psittacanthus sp. & $*$ & $*$ & & 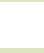 & & & & & 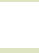 & & & & & & & 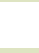 & & & & & 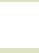 & $*$ & & $*$ \\
\hline Lythraceae & & & & & & & & & & & & & & & & & & & & & & & & \\
\hline Cuphea micrantha Kunth & & & & $*$ & $*$ & $*$ & $*$ & * & $*$ & & & $*$ & $*$ & $*$ & $*$ & $*$ & $*$ & $*$ & $*$ & $*$ & $*$ & $*$ & & $*$ \\
\hline Cuphea racemosa (L.f.) Spreng. & & & & & $*$ & $*$ & $*$ & $*$ & $*$ & & & $*$ & $*$ & $*$ & $*$ & $*$ & $*$ & $*$ & * & $*$ & $*$ & $*$ & & $*$ \\
\hline Malpighiaceae & & & & & & & & & & & & & & & & & & & & & & & & \\
\hline Byrsonima sericea DC. & $*$ & $*$ & 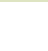 & $*$ & 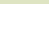 & & 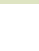 & & 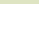 & & & $*$ & & . & & . & 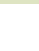 & & & $*$ & $*$ & $*$ & & \\
\hline Stigmaphyllon paralias A.Juss. & & $*$ & $*$ & $*$ & $*$ & & & & & & & $*$ & & & & & $*$ & $*$ & $*$ & $*$ & $*$ & $*$ & & \\
\hline Malvaceae & & & & & & & & & & & & & & & & & & & & & & & & \\
\hline $\begin{array}{l}\text { Pavonia cancellata (L.) Cav. } \\
\text { Sida sp. }\end{array}$ & $*$ & $*$ & $*$ & $*$ & $*$ & $*$ & $*$ & $*$ & $\begin{array}{l}* \\
*\end{array}$ & $\begin{array}{l}* \\
*\end{array}$ & $\begin{array}{l}* \\
*\end{array}$ & $\begin{array}{l}* \\
*\end{array}$ & $*$ & $*$ & $*$ & $*$ & $*$ & $*$ & * & $*$ & $*$ & $*$ & $*$ & $*$ \\
\hline Sida cordifolia L. & & & $*$ & $*$ & & $*$ & $*$ & $*$ & $*$ & $*$ & $*$ & $*$ & $*$ & $*$ & $*$ & $*$ & $*$ & $*$ & $*$ & $*$ & $*$ & & & $*$ \\
\hline Waltheria indica $\mathrm{L}$. & & & & $*$ & $*$ & $*$ & $*$ & $*$ & $*$ & $*$ & $*$ & $*$ & $*$ & $*$ & $*$ & $*$ & $*$ & $*$ & $*$ & $*$ & $*$ & & & $*$ \\
\hline Melastomataceae & & & & & & & & & & & & & & & & & & & & & & & & \\
\hline Miconia albicans (Sw.) Triana & $*$ & & & & & & & & & & & & & & & & & $*$ & $*$ & & & & & \\
\hline Pleroma lhotzkyanum (C. Presl.) Triana & & & & & & & & & $*$ & $*$ & $*$ & & & & & $*$ & $*$ & $*$ & & & & & & \\
\hline Nyctaginaceae & & & & & & & & & & & & & & & & & & & & & & & & \\
\hline Guapira pernambucensis (Casar.) Lundell & & & & & & & & & & $*$ & & & & & & $*$ & $*$ & & & & & & & \\
\hline Plantaginaceae & & & & & & & & & & & & & & & & & & & & & & & & \\
\hline Stemodia foliosa Benth. & & & & & & & & & & & & & & & & & & & & & & & & \\
\hline
\end{tabular}


Pelo menos 30 espécies $(37,5 \%)$ tiveram suas flores visitadas por meliponíneos, permitindo registrar qual recurso floral foi explorado (Tabela 1). Dentre as espécies de abelhas disponíveis no meliponário local, foram confirmadas em visitas às angiospermas observadas: Frieseomelitta doederleini, F. meadewaldoi, Scaptotrigona xanthotricha, e Tetragonisca angustula (Tabela 1). Dentre as espécies de angiospermas visitadas, a maioria apresenta hábito herbáceo (16 spp., 53,33\%), seguida das arbustivas (6 spp., 20\%), arbóreas (4 spp., 13,33\%), e o menor número de espécies visitadas foi de subarbustivas e trepadeiras ( 2 spp., 6,67\% cada). Para o primeiro período de observação (2015), o mês de agosto registrou o maior número espécies em floração (26-86,66\%), ao contrário de fevereiro, com o menor número (13-43,33\%). No segundo período de acompanhamento (2017/2018), o maior número de espécies em floração ocorreu em setembro e outubro/2017 (26-86,66\% cada) e o menor número em junho/2017 e maio/2018 (15-50\% cada).

Dentre as 30 espécies de angiospermas visitadas, B. verticillata, C. prasiifolia, C. erecta, M. pudica, R. grandiflora e T. subulata floresceram continuamente durante todo o período de observação. Apenas seis espécies apresentaram floração mais curta (Chamaecrista swainsonii, Psittacanthus sp., Senna macranthera, Senna splendida, Tapirira guianensis e Verbesina macrophylla), por período igual ou inferior a seis meses. As demais espécies visitadas (18) não apresentaram florescimento contínuo, porém, ofertaram recursos por 12 meses ou mais, considerando todo o período amostral (Tabela 2). Para as espécies de angiospermas visitadas pelos meliponíneos na área de estudo, 17 (56,67\%) foram fornecedoras de néctar: Alternanthera tenella, Anacardium occidentale, B. verticillata, Centratherum punctatum, C. erecta, C. prasiifolia, Croton beliotropiifolius, Hexasepalum radula, Lantana camara, Marsypianthes chamaedrys, Mitracarpus strigosus, Rhaphiodon echinus, Serjania salzmanniana, T. guianensis, T. subulata, Varronia curassavica, além de Psittacanthus sp. Outras sete espécies (23,33\%) forneceram pólen: Chamaecrista flexuosa, C. swainsonii, S. macranthera, S. splendida, Solanum paniculatum, Urochloa brizantha e V. macrophylla, e em outras seis espécies $(20 \%)$ foi observada a visita de meliponíneos, em momentos distintos, tanto para a coleta de pólen, quanto de néctar: Conyza bonariensis, Lepidaploa cotoneaster, M. pudica, R. grandiflora, Spondias tuberosa e Waltheria indica (Tabela 1).

Os meses com maior disponibilidade de recurso floral no primeiro período de estudo foram junho e julho de 2015 (14 nectaríferas, seis polinífero-nectaríferas e quatro poliníferas), agosto de 2015 (14 nectaríferas, seis polinífero-nectaríferas e seis poliníferas) e dezembro de 2015 (15 nectaríferas, seis polinífero-nectaríferas e cinco poliníferas). No segundo período, destacam-se os meses de agosto de 2017 (14 nectaríferas, cinco poliníferonectaríferas, cinco poliníferas), setembro e outubro de 2017 (15 nectaríferas, seis polinífero-nectaríferas, cinco poliníferas), novembro e dezembro de 2017 (15 nectaríferas, seis polinífero-nectaríferas, três poliníferas). Apenas para Stigmaphyllon paralias (Malpighiaceae) foram encontrados dados que indicam a mesma apenas como fonte de óleo, não sendo encontradas informações sobre potenciais recursos florais para as demais 26 espécies (Tabela 1). A análise de correlação mostrou que a presença e ausência de flores durante o período de estudo não apresentou correlação significativa ( $>>0,05)$, com os fatores climáticos (temperatura média, precipitação e umidade) analisados (Tabela 3).

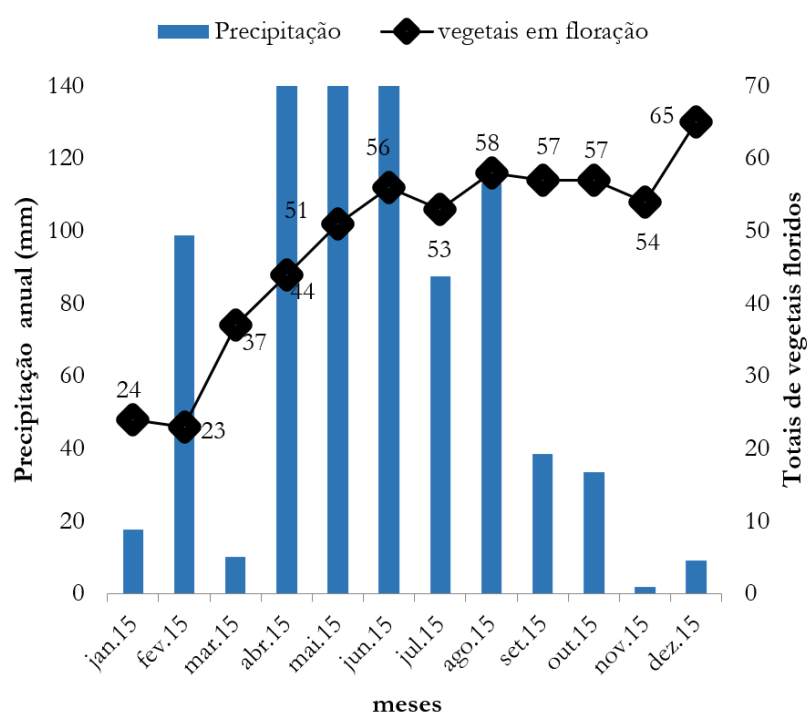

Figura 9. Relação entre precipitação e número de espécies floridas em área de Mata Atlântica, município de Alagoinhas-BA no primeiro período amostral (janeiro a dezembro de 2015).

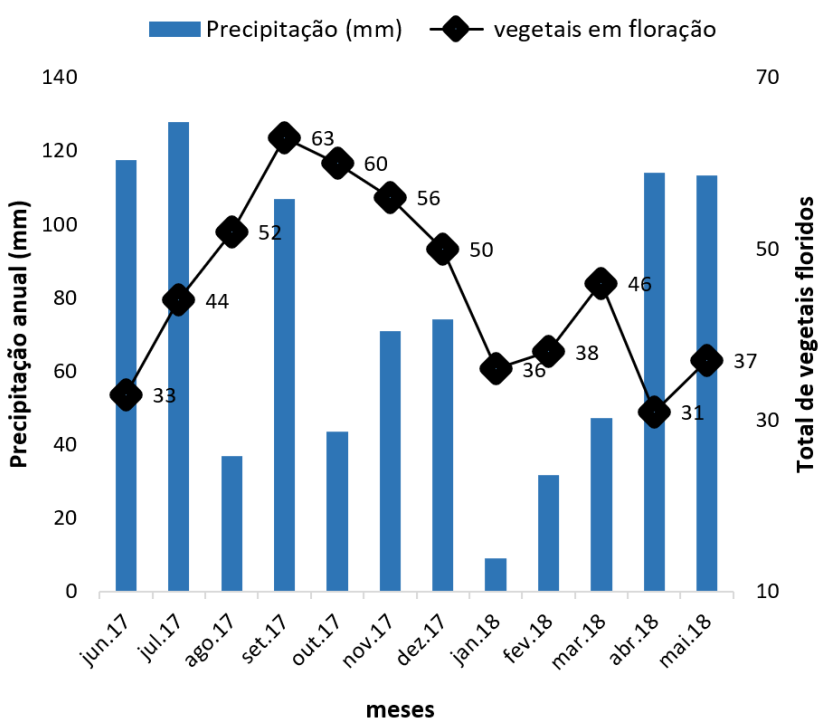

Figura 10. Relação entre a precipitação e o número de espécies floridas em área de Mata Atlântica, município de Alagoinhas-BA no para o segundo período amostral (junho de 2017 a maio de 2018).

Tabela 3. Valores da correlação de Spearman entre a temperatura média, a precipitação e a umidade com a atividade de floração (presença/ausência) de flores, Alagoinhas-BA, 2015-2017/2018.

\begin{tabular}{|c|c|c|c|}
\hline \multirow{2}{*}{ Anos } & \multicolumn{3}{|c|}{ Fatores climáticos } \\
\hline & Umidade & Precipitação & Temperatura \\
\hline $\begin{array}{c}2015 \\
\text { (jan/dez) }\end{array}$ & $\begin{array}{c}r=0,83719 \\
p=(-0,06655)\end{array}$ & $\begin{array}{c}r=0,82266 \\
p=(0,056042)\end{array}$ & $\begin{array}{c}r=0,50491 \\
p=(-0,21366)\end{array}$ \\
\hline $2017 / 2018$ & $\begin{array}{c}\mathrm{r}=0,712288 \\
\mathrm{p}=(-0,11888)\end{array}$ & $\begin{array}{c}r=0,42992 \\
p=(-0,25175)\end{array}$ & $\begin{array}{c}r=0,51284 \\
p=(-0,20979)\end{array}$ \\
\hline
\end{tabular}




\section{Discussão}

A lista de angiospermas apresentada para o entorno do meliponário analisado está totalmente em concordância com os dados previamente apresentados por Jesus et al. (2017), sendo confirmada a ocorrência de $87,5 \%$ de espécies nativas da flora brasileira, de acordo com a recente revisão da Flora do Brasil 2020. Isso demonstra que a área estudada inclui um importante fragmento de vegetação nativa, que merece mais atenção do ponto de vista da conservação da flora local. Apenas sete espécies presentes na área de estudo não são nativas do Brasil, sendo naturalizadas e pertencentes às famílias Asteraceae (3 spp.), Poaceae (2 spp.), além de uma espécie de Acanthaceae e uma de Verbenaceae (Flora do Brasil 2020). As duas espécies endêmicas da Mata Atlântica e ocorrentes nessa área têm distribuição mais ampla nesse bioma, sendo Pleroma lhotskyanum (Melastomataceae) e Guapira pernambucensis (Nyctaginaceae), ocorrentes também no Sudeste e outros estados do Nordeste (Guimarães, 2020; Rosseto et al., 2020, respectivamente). A ocorrência de mais 15 espécies endêmicas de outros Domínios fitogeográficos brasileiros demonstra o caráter transicional da vegetação da área de estudo, consistindo em um ecótono entre a Caatinga e a Mata Atlântica, com manchas de Cerrado, conforme mencionado por Jesus et al. (2017).

Asteraceae, Fabaceae, e Rubiaceae, reconhecidas como as famílias com maior representatividade no entorno do meliponário, tiveram maior número de espécies na área, as quais estão entre aquelas de maior riqueza na Mata Atlântica como um todo, incluindo os levantamentos florísticos desenvolvidos na Mata Atlântica do litoral norte e agreste da Bahia (Stehmann et al., 2009; Gomes; Guedes, 2014; Alves et al., 2015; Jesus et al., 2017). Estas famílias são consideradas importantes plantas melitófilas da flora nordestina e são frequentemente visitadas pelas abelhas Meliponini (Ramalho et al., 1990; Santos et al., 2018).

Com base nos resultados aqui apresentados, as famílias mais representativas em número de espécies (Asteraceae, Fabaceae e Rubiaceae), foram importantes famílias fornecedoras de recursos florais para os meliponíneos na área de estudo, tendo em vista a sua grande representatividade na flora amostrada. Dentre as outras famílias identificadas no entorno do meliponário, Euphorbiaceae, Boraginaceae, Commelinaceae, Portulacaceae, Verbenaceae e Anacardiaceae também são consideradas como importantes para abelhas no fornecimento de néctar e pólen (Silva, 2006; Muniz; Brito, 2007; Marques et al., 2007; Chaves et al., 2007; Melo, 2008; Sodré et al., 2008; Vidal et al., 2008; Conceição, 2013), sendo citadas como abrigo para as colmeias, como no caso de Spondias tuberosa Arruda (Anacardiaceae) (Santos et al., 2018).

Com base nos dados aqui apresentados, existe uma grande representatividade de plantas herbáceas compondo elementos pioneiros da flora local, como as espécies de Asteraceae, Poaceae, Cyperaceae e algumas Lamiaceae, conforme previamente indicado por Jesus et al. (2017). Sabe-se que a vegetação herbácea constitui a principal fonte de pólen e néctar para as Meliponini, principalmente no período das chuvas e na transição chuva-seca (Freitas, 1996; Carvalho; Marchini, 1999; Lopes et al., 2016). O estrato herbáceo também foi considerado o mais representativo em outros estudos envolvendo a flora melitófila (Locatelli et al., 2004; Santos et al., 2006; Pinheiro et al., 2008; Silva, 2014; Salis et al., 2015).

Quanto à exploração e à oferta de recursos florais, observou -se que a maioria das plantas, visualmente visitadas pelos Meliponini ou simplesmente em floração durante o acompanhamento, ofertou néctar a essas abelhas. Ao analisar amostras de mel de Tetragonisca angustula, Novais et al. (2015) afirmaram que, provavelmente, para suprir a demanda de néctar para produção de mel, essa espécie de abelha necessitaria forragear um maior número de plantas em busca de néctar, quando comparada à exploração por pólen. No caso da coleta de pólen, os mesmos autores ainda explicaram que esse recurso floral é explorado em um número menor de plantas, porém, isso não indica um esforço menor de coleta. Segundo Leal e Silva (2003), o néctar é considerado como a mais importante recompensa para os polinizadores e é referido como o recurso floral mais abundante em espécies de qualquer sistema de polinização e ecossistemas (Machado; Lopes, 2006). Desta forma, Biesmeijer et al. (1999) afirmam que os meliponíneos são capazes de selecionar néctar, o que influencia o forrageio dos visitantes (Fidalgo; Kleinert, 2010). As observações das visitas de meliponíneos às plantas na área de estudo apresentaram o mesmo cenário, com a maioria das plantas visitadas sendo nectaríferas e um menor número, poliníferas.

Dentre as espécies de angiospermas que foram observadas sendo visitadas pelos meliponíneos na área de estudo, Alternanthera tenella, Anacardium occidentale, Borreria verticillata, Centratherum punctatum, Commelina erecta, Conocliniopsis prasiifolia, Marsypianthes chamaedrys, Mimosa pudica, Raphiodon echinus, Richardia grandiflora, Senna macranthera, Spondias tuberosa, Tapirira guianensis, Turnera subulata e Waltheria indica foram referidas em várias listas de plantas melitófilas como importantes fontes de néctar e pólen para essas abelhas (Carvalho; Marchini, 1999; Vidal et al., 2008; Vieira et al., 2008; Maia-Silva, 2012). Contudo, outras espécies como Byrsonima sericea, Centrosema brasilianum, Pavonia cancellata, Sida cordifolia, Stylosanthes viscosa e Zornia latifolia, apesar de não terem sido observadas sendo visitadas pelos meliponíneos no presente trabalho, também são igualmente citadas como importantes componentes da flora melitófila (Aguiar et al., 2003; Machado; Lopes, 2006; Costa et al., 2006; Maia-Silva et al., 2012).

Adicionalmente, a montagem do calendário de floração aqui apresentado permitiu visualizar a disponibilidade dos recursos tróficos ofertados e a serem explorados pelos meliponíneos ao longo de todo o ano, nos dois períodos de observações. Essa informação sobre a floração das espécies na área pode ser considerada extremamente importante para as atividades meliponícolas, uma vez que infere a época de disponibilidade de recursos tróficos para as abelhas e também permite planejar o manejo do pasto meliponícola, conservando espécies e recompondo a área com aquelas plantas mais importantes (Almeida et al., 2003).

Comparando os dados climáticos para os dois períodos estudados, verificou-se que as precipitações ocorreram de forma atípica no segundo período amostrado, compreendendo um período com muita chuva durante todo o período estudado, porém, não influenciando a oferta dos recursos disponibilizados, já que estes se mantiveram constantes. Isso quer dizer que as espécies da área floresceram durante toda a estação chuvosa, até início da estação seca em ambos os períodos estudados, como também observado por Loca- 
telli et al. (2004), nos brejos de altitude em Pernambuco e Paraíba, e por Lopes et al. (2016), na Mata Atlântica do sul da Bahia.

Esses resultados diferem, no entanto, de outros ecossistemas tropicais, onde a maioria das espécies floresce por períodos curtos (Heithaus 1979; Pedro, 1992; Faria, 1994; Martins, 1995). Esses autores discutiram que, em comunidades submetidas ao estresse (interferências antrópicas ou situações climáticas adversas), onde usualmente o sistema de polinização é generalista, predominam longos períodos de florescimento, como provavelmente acontece na área estudada.

A ausência de correlação no florescimento de espécies tropicais com os fatores climáticos para as espécies estudadas pode estar relacionada mais com as condições endógenas (fisiológicas, nutricionais, edáficas, modo de reprodução) e pelos vetores ecológicos (predação, competição, polinização) do que somente a variáveis climáticas (Borchet, 1983; Schaik et al., 1993; Alencar, 1994). Isso consequentemente afeta a disponibilidade de recursos florais e influencia diretamente a dieta das abelhas, as quais podem apresentar diferentes graus de especialização e generalização na escolha, coleta e utilização dos recursos florais.

De acordo com Freitas (1991), a duração da floração possibilita um fluxo contínuo de pólen e néctar ao longo do ano. Na área de estudo, embora a oferta de recursos florais tenha sido mantida em todo o período de observação, pelo menos seis espécies - Borreria verticillata, Conocliniopsis prasïfolia (Asteraceae), Commelina erecta (Commelinaceae), Mimosa pudica (Fabaceae), Richardia grandiflora (Rubiaceae) e Turnera subulata (Turneraceae) - podem ser apontadas como importantes para a alimentação dos meliponíneos, sendo as únicas a manter um fluxo contínuo de pólen e/ou néctar para as abelhas durante o estudo. Assim, pode-se afirmar que esse padrão de concentração das visitas das abelhas sem ferrão a poucas espécies dentro de uma flora melitófila é comum para ambientes tropicais (Ramalho et al., 1990; Viana et al., 2006). Além disso, algumas plantas são exploradas como fonte de recursos tróficos esporádicos, apresentando também importância na manutenção das colônias como fontes complementares durante períodos de escassez de flores (Velthuis, 1997; Rodrigues et al., 2003).

Autores como Velthuis (1997) e Rodrigues et al. (2003) explicam ainda que meliponíneos podem buscar determinada fonte de recursos tróficos em detrimento de outra, em vista da facilidade de coleta, da qualidade e da quantidade de recursos fornecidos e da interação com os competidores. Isso pode explicar o número reduzido de plantas visitadas como parte do presente trabalho, uma vez que dentre as 80 espécies identificadas, em apenas 30 foram visitadas por esses insetos. Assim, pode-se inferir que mesmo com uma vasta oferta de flores em campo, nem todas são visitadas, provavelmente em função da partição de recursos tróficos com outros visitantes, assim como pela própria morfologia floral de algumas espécies, que pode limitar o acesso às recompensas. Carvalho e Marchini (1999) também observaram essa seleção de algumas fontes de recursos tróficos em um universo maior de plantas em floração, e argumentaram que podem existir plantas que não exercem atração sobre as abelhas.

As espécies citadas anteriormente, juntamente às demais apontadas na lista daquelas visitadas pelos meliponíneos, são consideradas potenciais fornecedoras de recursos florais importantes à sobre- vivência das abelhas no fragmento estudado, podendo ser utilizadas no manejo e na conservação dos polinizadores e da flora associada. Dessa forma, através da identificação da flora explorada pelos meliponíneos, foi possível indicar as prováveis fontes de pólen e néctar necessárias para a manutenção das colônias dessas abelhas.

\section{Conclusão}

Em relação à flora meliponícola identificada, as famílias de angiospermas que mais se destacaram quanto ao número de espécies registradas foram Asteraceae, Fabaceae e Rubiaceae. A vegetação herbácea, além de abundante na área de estudo, floresceu praticamente durante o ano todo, concordando com várias listas de espécies fornecedoras de recursos tróficos aos meliponíneos. Além disso, conheceu-se a potencialidade para 30 espécies visitadas por meliponíneos, com destaque para Borreria verticillata (Rubiaceae), Conocliniopsis prasiifolia (Asteraceae), Commelina erecta (Commelinaceae), Mimosa pudica (Fabaceae), Richardia grandiflora (Rubiaceae) e Turnera subulata (Turneraceae), que mantiveram um fluxo contínuo de pólen e/ou néctar para essas abelhas durante o estudo, sendo consideradas um importante pasto meliponícola para a guilda de abelhas na área de estudo.

O calendário de floração apresentado revelou dados da atividade de florescimento das espécies, constituindo uma importante fonte de informações sobre a época de florescimento ao longo dos anos e disponibilidade de recursos tróficos em uma flora local, além de indicar os períodos de maior florescimento, possibilitando descobrir quais as plantas importantes para a sobrevivência das abelhas dessa área.

Embora o fragmento de Mata Atlântica estudado apresente uma rica flora, incluindo $87,5 \%$ de representantes nativos do Brasil e duas espécies endêmicas deste bioma, consideramos muito importante a realização de estudos complementares, que avaliem outros fatores essenciais para o detalhamento da flora melitófila da área estudada. Recomenda-se também o estudo da biologia floral e análises palinológicas dos recursos florais das espécies inventariadas no entorno de outros meliponários, visando conhecer a disponibilidade do recurso trófico ofertado, e também as interações entre flores e visitantes florais. Assim, as informações contidas neste trabalho podem ser utilizadas em programas de implantação, manutenção e ampliação de pastos meliponícolas, contribuindo para o desenvolvimento e fortalecimento da atividade apícola local e regional.

\section{Agradecimentos}

Os autores agradecem a todos os taxonomistas envolvidos nas identificações das espécies vegetais, aos colegas do Laboratório de Micromorfologia Vegetal (LAMIV) da Universidade Feira de Santana (UEFS) e do Laboratório de Estudos Palinológicos (LAEP) da Universidade do Estado da Bahia (UNEB), pelo apoio técnico. À Fundação de Amparo à Pesquisa do Estado da Bahia (FAPESB), pelo apoio à infraestrutura do PPGBot/UEFS (processo PIE 009/2016), e à Coordenação de Aperfeiçoamento de Pessoal de Nível Superior - Brasil (CAPES) - Código de Financiamento 001, que concedeu também bolsa PNPD para MCD. E, ainda, ao Con- 
selho Nacional de Desenvolvimento Científico e Tecnológico (CNPq), pela bolsa de mestrado concedida à primeira autora e pela bolsa de produtividade em pesquisa concedida à RPO (PQ1C).

\section{Financiamento}

Ao Conselho Nacional de Desenvolvimento Científico e Tecnológico (CNPq), pela bolsa de mestrado concedida à primeira autora.

\section{Contribuições de Autoria}

Conceptualização: SOS, MCD. Curadoria de dados: SOS, MCD. Análise formal: MCD, RPO e LCL. Aquisição de financiamento: MCD, RPO. Investigação: SOS. Metodologia: SOS, MCD. Administração do projeto: SOS, MCD. Recursos: MCD, RPO. Programas: SOS, MCD, RPO. Supervisão: MCD, RPO, LCL. Validação: MCD. Visualização: MCD, RPO e LCL. Redação- rascunho original: SOS. Redação - revisão e edição: SOS, MCD, RPO, LCL.

\section{Conflito de Interesse}

Os autores declaram não haver conflitos de interesse a informar.

\section{Disponibilidade dos Dados}

Os dados integrais analisados durante o estudo estão apresentados no corpo do manuscrito e os espécimes estão depositados no herbário da Universidade do Estado da Bahia - HUNEB (Campus II)

\section{Conformidade Ética}

Não se aplica.

\section{Referências}

Aguiar CML. Utilização de recursos florais por abelhas (Hymenoptera, Apoidea) em uma área de caatinga (Itatim, Bahia, Brasil). Revista Brasileira de Zoologia 2003;20(3):457-467. doi:10.1590/S0101-81752003000300015

Aguiar CML, Zanella FCV, Martins CF, Carvalho CAL. Plantas visitadas por Centris spp. (Hymenoptera: Apidae) na Caatinga para obtenção de recursos florais. Neotropical Entomology 2003;32(2): 247-259. doi:10.1590/S1519-566X2003000200009

Aguiar CML, Gaglianone MC. Nesting biology of Centris (Centris) aenea Lepeletier (Hymenoptera, Apidae, Centridini). Revista Brasileira de Zoologia 2003;20(4):601-606. doi:10.1590/S0101$\underline{81752003000400006}$

Aleixo KP, Faria LB, Groppo M, Castro MMN, Silva CI. Spatiotemporal distribution of floral resources in a Brazilian city: implications for the maintenance of pollinators, especially bees. Urban Forestry \& Urban Greening 2014;13(4):689-696. doi:10.1016/ j.ufug.2014.08.002

Alencar JC. Fenologia de cinco espécies arbóreas tropicais de Sapotaceae correlacionada a variáveis climáticas na Reserva Ducke, Manaus. Acta Amazonica 1994;24(3):161-182. doi:10.1590/1809 $-43921994243182$

Almeida NM, Machado IC. Estudo comparativo da biologia floral, polinização e reprodução em duas espécies de Cuphea $\mathrm{P}$. Br. (Lythraceae). In: Anais do $56^{\circ}$ Congresso Nacional de Botânica; 2005 out 9-_14; Curitiba, PR. Curitiba: SBB; 2005.

Almeida DD, Marchini LC, Sodré GS, D’ávila M, Arruda CMF. Plantas visitadas por abelhas e polinização. Piracicaba: ESALQ; 2003.

Alves M, Rodrigo BO, Teixeira SR., Guedes MLS, Roque N. Levantamento florístico de um remanescente de Mata Atlântica no litoral norte do estado da Bahia, Brasil. Hoehnea 2015;42(3):581_ 595. doi:10.1590/2236-8906-06/2015

Azpeitia F, Lara C. Reprodutive biology and pollination of the parasitic plant Psittacanthus calyculatus (Loranthaceae) in central México. Journal of the Torrey Botanical Society 2006;133(3):421 -428. doi: $10.3159 / 1095-5674$
Barrows EM. Nectar robbing and pollination of Lantana camara (Verbenaceae). Biotropica 1976;8(2):132-135. doi: $10.2307 / 2989633$

Bawa KS. Patterns of flowering in tropical plants. In: Jones CE, Little RJ, editors. Handbook of experimental pollination biology. New York: Scientific and Academic Editions; 1983. p. 394-410.

Braga R. Plantas do Nordeste, especialmente do Ceará. 2. ed. Natal: Editora Universitária da UFRN; 1960.

Biesmeijer JC, Richter JAP, Smeets MAJP, Sommeijer MJ. Niche differentiation in nectar-collecting stingless bees: the influence of morphology, floral choice and interference competition. Ecologycal Entomology 1999;24(4):380-388. doi:10.1046/j.13652311.1999.00220.x

Bogdan AV. Grass pollination by bees in Kenya. Proceedings of the Linnean Society 1962;173(10):57--173. doi:10.1111/ j.10958312.1962.tb01326.x

Borchet R. Phenology and control of florwering in tropical trees. Biotropica 1983;15(2):81-89. doi:10.2307/1936825

Buchmann SL. Buzz pollination in angiosperms. In: Jones CE, Little RJ, editors. Handbook of experimental pollination biology. New York, Scientific and Academic Editions 1983;73-113.

Cane JH. Breeding biologies, seed production and species-rich bee guilds of Cleome lutea and Cleome serrulata (Cleomaceae). Plant Species Biology 2008;23(3):152-158. doi:10.1111/j.14421984.2008.00224.x

Carvalho CAL, Marchini LC. Plantas visitadas por Apis mellifera L. no vale do rio Paraguaçu, município de Castro Alves, Bahia. Revista Brasileira de Botânica 1999;22(2):333-338.

Chaves EMF, Barros RFM, Araújo FS. Flora apícola do Carrasco no Município de Cocal, Piauí, Brasil. Revista Brasileira de Biociências 2007; 5(1):555-557.

Coelho M, Amorim AM. Floristic composition of the Montane Forest in the Almadina-Barro Preto axis, Southern Bahia, Brazil Biota Neotropica 2014;14(1):1-41. doi:10.1590/S1676-06033878

Costa CBN, Costa JAS, Ramalho M. Biologia reprodutiva de espécies simpátricas de Malpighiaceae em dunas costeiras da Bahia, Brasil. Revista Brasileira de Botânica 2006;29(1):103-114. doi:10.1590/S0100-84042006000100010

Covre C, Guerra TM. Espécies melitóflas da restinga do Parque Estadual Paulo César Vinha, Espírito Santo, Brasil. Boletim do Museu de Biologia Mello Leitão 2016;38(2):73-90.

Conceição PJ. Levantamento florístico e perfil botânico do pólen (samburá) da abelha Melipona quadrifasciata anthidioides Lepeletier, 1836 (Hymenoptera: Apidae) da região semiárida, estado da Bahia [dissertação]. Cruz das Almas, BA: Universidade Federal do Recôncavo da Bahia; 2013.

Endress PK. Diversity and evolutionary biology of tropical flowers Cambridge University Press; 1994.

Faria GM. A flora e a fauna apícola de um ecossistema de campo rupestre, Serra do Cipó - MG Brasil: Composição, fenologia e suas interações [tese]. Rio Claro, SP: Universidade Estadual Paulista; 1994

Fernandes MM, Venturieri GC, Jardim MAG. Biologia, visitantes florais e potencial melífero de Tapirira guianensis (Anacardiaceae) na Amazônia Oriental. Rev. Cienc. Agrar. 2012;55(3):167-175. doi:10x4322:ocax2012x58

Freitas BM. Potencial da Caatinga para produção de pólen e néctar para exploração apícola [dissertação]. Fortaleza, CE: Departamento de Zootecnia da Universidade Federal do Ceará; 1991.

Freitas BM. Caracterização do fluxo nectário e pólen na caatinga do Nordeste. In: Anais do $11^{\circ}$ Congresso Brasileiro de Apicultura. 1996 nov 26-30; Teresina, PI. Teresina, PI: CBA; 1996.

Freitas BM, Silva EMS. Potencial apícola da vegetação do semiárido Brasileiro. In: Santos FAR, editor. Apium Plantae. Recife, PE: MCT; 2006. p. 19-32. 
Freeman EC, Worthington RD, Jackson MS. Floral nectar sugar compositions of some south and southeast Asian species. Biotropica 1991;23(4b):568-574. doi:10.2307/2388394

Fidalgo AO, Kleinert AMP. Floral preferences and climate influence in nectar and pollen foraging by Melipona rufiventris in Ubaturba, São Paulo, Brazil. Neotropical Entomology 2010;39(6):879 -884. doi: 10.1590/S1519-566X2010000600005

Flora do Brasil 2020. Jardim Botânico do Rio de Janeiro [internet]. Rio de Janeiro: JBRJ [citado em 7 out 2021]. Disponível em: http:/ / floradobrasil.jbrj.gov.br/

Fundação SOS Mata Atlântica, Instituto Nacional de Pesquisas Espaciais. Atlas dos remanescentes florestais da Mata Atlântica: relatório técnico: período 2016-2017 [internet]. São Paulo: Fundação SOS Mata Atlântica, INPE; 2018 [acesso em 18 maio 2018]. Disponível em: http://www.sosma.org.br/projeto/atlasda-mata-atlantica/dados-mais-recentes/

Giulietti AM, Queiroz LP, Santos TR, França F, Guedes ML, Amorim AM. Flora da Bahia. Sitientibus - série Ciências Biológicas; 2006.

Gomes FS, Guedes MLS. Flora vascular e formas de vida das formações de restinga do litoral norte da Bahia, Brasil. Acta Biologica Catarinense 2014;1(1):22-43. doi: 10.21726/abc.v1i1.82

Guimarães PJF. Pleroma. In: Flora do Brasil 2020. Jardim Botânico do Rio de Janeiro [internet]. Rio de Janeiro: JBRJ [citado em 7 outubro de 2021]. Disponível em: http:/ / floradobrasil.jbrj.gov.br/reflora/floradobrasil/FB603039

Heithaus ER. Flower visitation records and resource overlap of bees and wasps in Northwest Costa Rica. Brenesia 1979;16(1)952.

Hoeltgebaum MP, Montagna T, Lando AP, Puttkammer C, Orth AI, Guerra MP, Reis M. Reproductive Biology of Varronia curassavica Jacq. (Boraginaceae). Anais da Academia Brasileira de Ciências 2016;90(1):59-71. doi:10.1590/0001-3765201820160273

Jesus NG, Almeida GSS, Fonseca MR. Diversidade florística de dois remanescentes de Floresta Ombrófila Densa. In: Nunes JMC, Matos MRB, editors. Litoral Norte da Bahia: caracterização ambiental, biodiversidade e conservação. Salvador, BA: EDUFBA; 2017. p. 455.

Kill LHP, Haji FNP, Lima PCF. Visitantes florais de plantas invasoras de áreas com fruteiras irrigadas. Scientia Agricola 2000;57 (3):575-580. doi:10.1590/S0103-90162000000300034

Kissmann KG, Groth D. Plantas infestantes e nocivas. São Paulo, SP: Basf; 2000.

King RM, Robinson H. The genera of The Eupatorieae (Asteraceae). New York: Missouri Botanical Garden; 1987.

Leal IR, Silva JMC. Ecologia e conservação da Caatinga. Recife: Editora Universitária da UFPE; 2003.

Lleras E. Trigoniaceae. Flora Neotropica. New York: NYBG; 1978.

Locatelli E, Machado IC, Medeiros P. Riqueza de abelhas e a flora apícola em um fragmento da mata serrana (Brejo de Altitude) em Pernambuco, Nordeste do Brasil. In: Porto KC, Cabral JJP, Tabarelli M, editors. Brejos de Altitude em Pernambuco e Paraíba (História Natural, Ecologia e Conservação). Brasília, DF: MMA; 2004.

Lopes CGR, Beirão DCC, Pereira LA, Alencar LC. Levantamento da flora apícola em área de cerrado no município de Floriano, estado do Piauí, Brasil. Revista Brasileira de Biociências 2016;14 (2):102-110.

Lopes LCM, Mariano-Neto E, Amorim AM. Estrutura e composição florística de uma comunidade lenhosa do sub-bosque em uma floresta Tropical no Brasil. Boletim do Museu de Biologia Mello Leitão 2015;37(4):361-391.

Lorenzi H. Plantas daninhas do Brasil: terrestres, aquáticas, parasitas e tóxicas. São Paulo: Instituto Plantarum; 2000.
Lorenzi H. Árvores brasileiras: manual de identificação e cultivo de plantas arbóreas nativas do Brasil. 2. ed. Nova Odessa, SP: Instituto Plantarum, EP-CEPEA; 2002.

Maia-Silva CS, Hrncir MCI, Queiroz RT, Imperatriz-Fonseca VL. Guia de plantas visitadas por abelhas na Caatinga. Fortaleza, CE: Editora Fundação Brasil Cidadão; 2012.

Machado IC, Lopes AV. Melitofilia em espécies de Caatinga em Pernambuco e estudos relacionados existentes no ecossistema. In: Giulietti AM, editor. Apium Plantae. Recife, PE: IMSEAR; 2006.

Marques LJP, Muniz FH, Silva JM. Levantamento apibotânico do município de Santa Luzia do Paruá, Maranhão: resultados preliminares. Revista Brasileira de Biociências 2007;5(1):114-116.

Martins CF. Flora apícola e nichos tróficos de abelhas (Hym., Apoidea) na Chapada Diamantina (Lençóis, BA, Brasil). Revista Nordestina de Biologia 1995;10(2):119-140.

Matos MRB, Queiroz EP, Bautista HP. Fitogeografia. In: Nunes JMC, Matos MRB, editors. Litoral Norte da Bahia: caracterização ambiental, biodiversidade e conservação. Salvador: EDUFBA; 2017. p. 455.

Melo PA. Flora apícola em Jequitibá, Mundo Novo-BA [dissertação]. Cruz das Almas, BA: Universidade Federal do Recôncavo da Bahia; 2008.

Meneguzzo MK. Fontes de alimentos usadas por abelhas (Hymenoptera, Apoidea) em áreas campestres da Floresta Densa Montana, no sul de Santa Catarina [trabalho de conclusão de curso]. Criciúma, SC: Universidade do Extremo Sul Catarinense; 2013.

MMA. Ministério do Meio Ambiente. Mapeamento da cobertura vegetal dos biomas brasileiros [internet]. Brasília: MMA. [citado em 26 jul 2018]. Disponível em: http://www.mma.gov.br/ estruturas/sbf chm rbbio/_arquivos/ mapas_cobertura_vegetal.pdf/

Mori AS, Silva LAM, Lisboa G, Coradin L. Manual de manejo do herbário fanerogâmico. Ilhéus, BA: CEPLAC-CEPEC; 1989.

Muniz FH, Brito ER. Levantamento da flora apícola do município de Itapecuru-Mirim, Maranhão. Revista Brasileira de Biociências 2007;5(1):111-113.

Nogueira-Neto P. Vida e criação de abelhas indígenas sem ferrão. São Paulo, SP: Nogueirapis; 1997.

Novais JS, Garcêz AC, Absy ML, Santos FAR. Comparative pollen spectra of Tetragonisca angustula (Apidae, Meliponini) from the Lower Amazon (N Brazil) and caatinga (NE Brazil). Apidologie 2015;46(4):417-431. doi:10.1007/s13592-014-0332-Z

Nunes-Silva P, Hrncir M, Imperatriz-Fonseca VL. Thoracic vibrations in stingless bees: is body size important for an efficient buzz pollination? Oecologia Australis 2010;14(1):140-151. doi: $10.4257 /$ oeco.2010.1401.07

Oliveira FPM, Carreira LMM, Jardim MAG. Caracterização polínica do mel de Apis mellifera L. em área de floresta secundária no município de Igarapé-Açu, Pará. Boletim do Museu Paraense Emílio Goeldi. Série Botânica 1998;14(2):159-178.

Oliveira U, Paglia AP, Brescovit AD et al. The strong influence of collection bias on biodiversity knowledge shortfalls of Brazilian terrestrial biodiversity. Diversity and Distributions 2016; 22 (12):1232-1244. doi:10.1111/ddi.12489

Pedro SRM. Sobre as abelhas (Hymenoptera, Apoidea) em um ecossistema de cerrado (Cajuru, NE do estado de São Paulo): composição, fenologia e visita às flores [tese]. Ribeirão Preto, SP: Universidade de São Paulo; 1992.

Pinheiro M, Abrão BE, Harter-Marques B, Miotto STS. Floral resources used by insects in a grassland community in southern Brazil. Revista Brasileira de Botânica 2008;31(3):469-489. doi:10.1590/S0100-84042008000300011 
Ramalho M, Kleinert-Giovannini A, Imperatriz-Fonseca VL. Important bee plants for stingless bees (Melipona and Trigonini) and Africanizad honey bees (Apis mellifera) in neotropical habitats: A review. Paris Apidologie 1990;21(5):469-488. doi:10.1051/ apido:19900508

Rezende CL, Scarano FR, Assadd ED et al. From hotspot to hopespot: an opportunity for the Brazilian Atlantic Forest. Perspectives in Ecology and Conservation 2018;16(4)208-214. doi:10.1016/i.pecon.2018.10.002

Roubik DW, Moreno PJE. Pollen and spores of Barro Colorado Island. St Louis: Monographs in Systematic Botany; 1991.

Roubik DW. Ecology and natural history of tropical bees. New York: Cambridge University Press; 1992

Rodrigues AE, Silva MAF da, Dornelas GS, Rodrigues ML. Estudo de plantas visitadas por abelhas melíponas na Microregião do Brejo no estado da Paraíba. Acta Scientiarum. Animal Sciences 2003;25(2):234-259. doi:10.4025/actascianimsci.v25i2.1988

Rossetto EFS, Sá CFC, Souza FS, Coelho AAOP. Guapira in Flora do Brasil 2020. Jardim Botânico do Rio de Janeiro. [internet]. Rio de Janeiro: JBRJ [citado em 7 out 2021]. Disponível em: http:/ / floradobrasil.jbrj.gov.br/reflora/floradobrasil/FB10914

Sakagami SF, Laroca S, Moure JS. Wild bee biocenotics in São José dos Pinhais (PR), South Brazil. Preliminary Report. Journal of the Faculty of Hokkaido University VI, Zoology 1967;19(2):190_ 250.

Salis SM, Jesus EM, Reis VDA, Almeida AM, Padilha DRC. Calendário floral de plantas melíferas nativas da Borda Oeste do Pantanal no Estado do Mato Grosso do Sul. Pesquisa Agropecuária Brasileira 2015;50(1):861-870. doi:10.1590/S0100204X2015001000001

Santana IN, Almeida GSS. Biologia Floral de Verbesina macrophylla (Cass.) S.F. Blake. In: Anais do Congresso Nordestino de Biólogos Congrebio 2016;(6):369-377. doi:10.21472/congrebio2016.et $\underline{-09-009}$

Santos, J.C., Leal, I.R., Almeida-Cortez, J.S., Fernandes, G.W. \& Tabarelli, M. (2011) Caatinga: the scientific negligence experienced by a dry tropical forest. Tropical Conservation Science, 4 , 276-28

Santos, J.C., Leal, I.R., Almeida-Cortez, J.S., Fernandes, G.W. \& Tabarelli, M. (2011) Caatinga: the scientific negligence experienced by a dry tropical forest. Tropical Conservation Science, 4 , 276-286

Santos JC, Leal IR, Almeida-Cortez JS, Fernandes GW, Tabarelli M. Caatinga: the scientific negligence experienced by a dry tropical forest. Tropical Conservation Science 2011;4(3):276-286. doi:10.1177/194008291100400306

Santos FAR, Oliveira JM, Oliveira PP, Leite KRB, Carneiro EC. Plantas do Semi-Árido importantes para as abelhas. In: Giulietti AM, Queiroz LP, editors. Apium Plantae. Recife, PE: IMSEAR; 2006. p. 61-86.

Schaik CPV, Terborgh JW, Wright SJ. The phenology of tropical forests - adaptive significance and consequences for primary consumers. Annual Review of Ecology and Systematics 1993;24 (1):353-377. doi:10.1146/annurev.es.24.110193.002033

SEI. Superintendência de Estudos econômicos e Sociais da Bahia. Estatísticas dos municípios baianos [internet]. Salvador: SEI; 2018 [citado em 8 ago 2018]. Disponível em: http:// www.sei.ba.gov.br/index.php? option $=\mathrm{com}$ content\&view $=$ article $\&$ id $=2441 \&$ Itemid $=284$

SILVA RA. Caracterização da flora apícola e do mel produzido por Apis mellifera L., 1758 (Hymenoptera: Apidae) no estado da Paraíba [tese]. João Pessoa, PB: Universidade Federal da Paraíba; 2006.
Silva JI. Diversidade da flora apícola e levantamento da apifauna no município de São João do Piauí [dissertação]. Teresina: Universidade Federal do Piauí; 2014.

Sodré GS, Marchini LC, Moreti ACCC, Carvalho CAL. Tipos polínicos encontrados em amostras de méis de Apis mellifera em Picos, Estado do Piauí. Ciência Rural 2008;38(3):839-842. doi:10.1590/S0103-84782008000300043

Shuel RW. Current research on nectar. Bee World 1970;51:63-70.

Stehmann JR, Forzza AS, Salino A, Sobral M. et al. Plantas da Floresta Atlântica. Rio de Janeiro: Jardim Botânico do Rio de Janeiro; 2009.

Thiers B. (continuously updated) Index herbariorum: a global directory of public herbaria and associated staf. New York Botanical Garden's Virtual Herbarium. [internet]. New York [acesso em 14 set 2018]. Disponível em: http://sweetgum.nybg.org/science/ ih/

The Brazil Flora Group. Growing knowledge: an overview of seed plant diversity in Brazil. Rodriguésia 2015;66(4):1085-1113.

Tripp EA, Manos PS. Is floral specialization an evolutionary deadend? Pollination system transitions in Ruellia (Acanthaceae). Evolution 2008;62(7):1712-1737. doi:10.1111/j.15585646.2008.00398.x

Varalakshmi P, Raju AJS. Psychophilous and melittophilous pollination syndrome in Tridax Procumbens L. (Asteraceae). Taprobanica 2013;5(2):124-130. doi:10.4038/tapro.v5i2.6286

Viana BF, Silva FO, Kleinert AMP. A flora apícola de uma área restrita de dunas litorâneas, Abaeté, Salvador, Bahia. Revista Brasileira de Botânica 2006;29(1):13-25. doi:10.1590/S0100$\underline{84042006000100003}$

Vidal MG, Santana NS, Vidal D. Flora apícola e manejo de apiários na região do Recôncavo sul da Bahia. Revista Acadêmica Ciências Agrárias 2008;6(4):503-509. doi:10.7213/ cienciaanimal.v6i4.11636

Vieira GHC, Marchini LC, Souza BA, Moreti ACCC. Fontes florais usadas por abelhas (Hymenoptera, Apoidea) em área de cerrado no município de Cassilândia, Mato Grosso do Sul, Brasil. Ciência e Agrotecnologia 2008;32(5):1454-1460. doi:10.1590/ $\underline{\mathrm{S} 141370542008000500015}$

Velthuis HW. Abelhas sem ferrão. São Paulo: Universidade de São Paulo; 1997.

Wiese H. Nova apicultura. 6. ed. Porto Alegre: Agropecuária; 1985. Wiese H. Apicultura. Novos tempos. 2. ed. Guaiba: Agrolivros; 2005.

\section{Como citar este artigo}

How to cite this article

\section{(ABNT)}

SANTOS, S. O.; DÓREA, M. C.; OLIVEIRA, R. P.; LIMA, L. C. L. Flora de interesse meliponícola em um fragmento de Mata Atlântica no litoral norte da Bahia, Brasil. Paubrasilia, Porto Seguro, v. 4, e0078, 2021. DOI 10.33447/paubrasilia.2021.e0078

\section{(Vancouver)}

Santos SO, Dórea MC, Oliveira RP, Lima LCL. Flora de interesse meliponícola em um fragmento de Mata Atlântica no litoral norte da Bahia, Brasil. Paubrasilia 2021;4:e0078. doi:10.33447/ paubrasilia.2021.e0078 